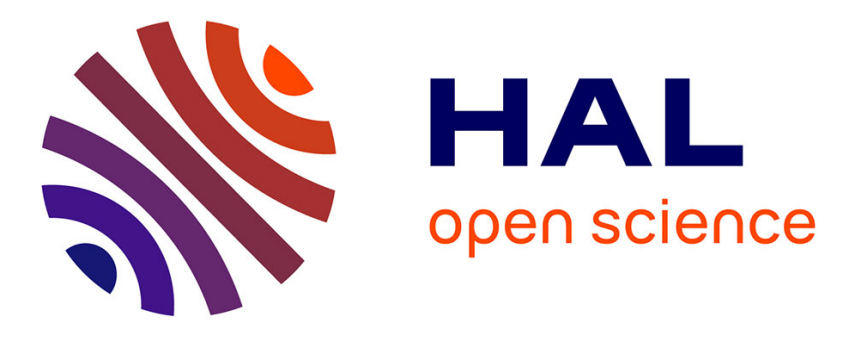

\title{
Molecular changes in mesothelioma with an impact on prognosis and treatment
}

\author{
Didier Jean, Julien Daubriac, Françoise Le Pimpec-Barthes, Françoise \\ Galateau-Salle, Marie-Claude Jaurand
}

\section{To cite this version:}

Didier Jean, Julien Daubriac, Françoise Le Pimpec-Barthes, Françoise Galateau-Salle, Marie-Claude Jaurand. Molecular changes in mesothelioma with an impact on prognosis and treatment. Archives of Pathology and Laboratory Medicine, 2012, 136 (3), pp.277-293. 10.5858/arpa.2011-0215-RA . inserm- 02478588

\section{HAL Id: inserm-02478588 https://www.hal.inserm.fr/inserm-02478588}

Submitted on 14 Feb 2020

HAL is a multi-disciplinary open access archive for the deposit and dissemination of scientific research documents, whether they are published or not. The documents may come from teaching and research institutions in France or abroad, or from public or private research centers.
L'archive ouverte pluridisciplinaire HAL, est destinée au dépôt et à la diffusion de documents scientifiques de niveau recherche, publiés ou non, émanant des établissements d'enseignement et de recherche français ou étrangers, des laboratoires publics ou privés. 
1

2 MOLECULAR CHANGES IN MESOTHELIOMA WITH AN IMPACT ON PROGNOSIS

3

AND TREATMENT

4 


\section{$5 \quad$ Abstract (250 words):}

7 Over recent decades, genetic and epigenetic abnormalities have been investigated in malignant pleural 8 mesothelioma (MPM) by studying gene mutations, DNA methylation, gene and miRNA expression 9 profiling. These researches have improved patients' outcomes by increasing our level of confidence in 10 MPM diagnosis and prognosis.

11 Molecular changes in MPM consist in altered expression, activation or inactivation of critical genes in 12 oncogenesis, especially tumor suppressor genes at the INK4 and NF2 loci. Deregulation of signaling pathways related to differentiation, survival, proliferation, apoptosis, cell cycle control, metabolism,

14 migration and invasion have been demonstrated in complementary studies. Activation of membrane

15 receptor tyrosine kinase has been frequently observed. More recent data have indicated the presence of 16 alterations that could be targeted at a global level (methylation). Molecular analyses of series of MPM 17 cases showed that defined alterations are generally present in MPM subsets, consistent with interindividual variations of molecular alterations. This suggests that identification of patient subgroups

19 will be essential in order to develop more specific therapies.

20 Some of the findings have already been used as the basis for several studies testing various targeted

21 clinical approaches mainly on specific receptor tyrosine kinases, but mostly with limited success.

22 Various experimental researches have been also developed, especially to abolish proliferation and 23 trigger apoptosis in MPM cells. Further basic research studies are needed to predict a positive 24 response in MPM, in order to avoid a rapidly unfavorable course and to prevent wasting resources 25 with inappropriate treatments. Demonstration of multiple alterations present in MPM should 26 encourage research into combined or more global therapies. 


\section{Introduction}

Over recent decades, various studies have been conducted to define the molecular characteristics of malignant mesothelioma (MM) cells. Genome-wide array-based approaches have allowed progress in MM research by identifying changes at the genetic and epigenetic levels. Genetic and epigenetic abnormalities have been investigated by identification of gene mutations, copy number changes, DNA methylation, and gene and miRNA expression profiling. The development of biological resources, frozen tissue and serum banks, tissue arrays and virtual banks, has also provided efficient tools to characterize MM cells and identify various types of tissue and serum markers. Reviews on genomic abnormalities and signal transduction dysregulation have been previously published ${ }^{1-3}$. The goal of this paper is to summarize the molecular changes in MM, focusing on more recent advances in malignant pleural mesothelioma (MPM), and discussing the level of confidence and limitations of these results, their impact on prognosis and treatment and the future research that is required to fill the gaps and enhance the benefit of basic research to improve the patient's outcome.

\section{Genomic and epigenetic changes in mesothelioma}

44 Genomic and epigenetic changes of potential interest for MPM histology, diagnosis and prognosis are described in Table 1.

\subsection{Chromosomal alterations}

Genomic alterations in human MPM have been previously reported in numerous studies based on various methods: cytogenetic analysis of standard karyotype, classical comparative genomic hybridization (CGH), CGH array, single nucleotide polymorphism (SNP) array and representational oligonucleotide microarray analysis (ROMA). Cytogenetic studies first demonstrated that numerous chromosomal abnormalities are associated with MPM, including both various structural and numerical

52 changes, and recurrent alterations ${ }^{4-5}$. These earlier studies have already been reviewed in detail ${ }^{1-2}$.

53 Table 2 shows the recurrent regions of chromosomal alterations reported in recent studies using high54 throughput analyses. MPM cell cultures and primary tumors both share similar patterns of chromosomal alterations. However, the frequency of alterations in some particular chromosomal 
regions is generally higher in cultured cells, likely due to the presence of normal cells in tumor samples as mentioned by several authors. Losses of chromosomal regions are always more common than gains. Frequent losses are localized on chromosomes 1p, 3p, 4q, 6q, 9p, 13q, 14q, and 22q and gains involve chromosomes $1 q, 5 p, 7 p, 8 q$ and $17 q^{6-12}$. A recent large-scale analysis of gene mutations based on second-generation sequencing in one tumor specimen confirmed the presence of numerous DNA rearrangements in MPM ${ }^{13}$.

Chromosomal alterations and clinicopathological features. Differences in genomic alterations have been described in MPM according to the histological subtype or the patient's asbestos exposure status. Although recurrent regions of chromosomal alterations are roughly similar between epithelioid and sarcomatoid MPM, significant differences in the frequency of genomic alterations have been observed, such as losses in chromosomal regions 3p14-p21, 8p12-pter, and 17p12-pter or gain in 7q ${ }^{6}$.

Experimental studies have shown that asbestos fibers induce chromosomal abnormalities in normal human mesothelial cells ${ }^{14-15}$. Significant correlations have been described between high contents of asbestos fibers in lung tissue and partial or total losses of chromosomes 1, 4 and 9, and chromosomal rearrangements involving a breakpoint at $1 \mathrm{p} 11-\mathrm{p} 22^{16-17}$. More recently, comparison between recurrent altered regions in asbestos-exposed and non-exposed patients showed a significant difference in the 14q11.2-q21 region, which was also lost in fiber-induced murine mesothelioma ${ }^{12}$.

Chromosomal alterations and diagnosis. None of the individual genomic aberrations observed are specific for MPM, as they are also found in other types of tumors. However, some of these genomic aberrations could be used to distinguish benign mesothelial proliferations from MPM. This is the case for the deletion involving the 9p21.3 locus, the site of the cyclin-dependent kinase inhibitor 2A gene $(C D K N 2 A)$ which is one of the most frequent alterations in MPM and is often homozygous. Detection of CDKN2A deletion by fluorescence in-situ hybridization (FISH) has therefore been evaluated for the diagnosis of MPM ${ }^{18-20}$. CGH analysis has also been used in an attempt to distinguish MPM from adenocarcinoma and large-cell anaplastic carcinoma of the lung. The frequency of several genomic alterations can be used to differentiate mesothelioma from lung carcinoma with a sensitivity and specificity of $89 \%$ and $63 \%$, respectively ${ }^{21}$. It has also been suggested that CGH analysis could be useful to distinguish sarcomatoid MPM from other types of spindle cell tumors of the pleura ${ }^{22}$. 
84 Chromosomal alterations and patient outcome. Correlations between patient survival and

85 chromosomal imbalance have also been studied. Chromosome copy number and alterations of the

86 short arm of chromosome 7 have been reported to be inversely correlated with survival ${ }^{16,23}$.

87 Univariate and multivariate analyses in a larger number of MPM showed that homozygous CDKN2A

88 deletion, detected by FISH analysis, is a significant independent adverse prognostic factor ${ }^{24-25}$.

89 Classification of MPM patients into two groups defined by short-term (less than 12 months) and long-

90 term recurrence after surgery also suggested an association between 9p21.3 deletion encompassing the

$91 C D K N 2 A$ locus and the short-term group ${ }^{9}$. In the same ROMA analysis, chromosomal instability

92 corresponding to the number of genomic alterations was shown to be higher in MPM patients

93 characterized by a shorter time to relapse ${ }^{9}$. In deciduoid MPM, a variant of epithelioid MPM, survival

94 was also found to be longer in patients with a smaller number of losses ${ }^{26}$. Interestingly, a correlation

95 was demonstrated between chromosomal instability and tumorigenicity of human mesothelioma

96 xenografts in nude mice ${ }^{12}$. These data indicate a correlation between the number of genomic

97 alterations and the aggressive behavior of MPM and further studies are needed to determine whether

98 chromosomal instability can be used as a prognostic factor.

99 Data on chromosome imbalance could also be useful to design new treatment strategies: a relevant

100 example targets the methylthioadenosine phosphorylase (MTAP) gene. Homozygous co-deletion of the

101 MTAP gene and the CDKN2A gene has been observed in the majority of pleural mesotheliomas ${ }^{24}$. The

102 MTAP gene is a key enzyme in the salvage pathway of AMP synthesis complementary of the de novo

103 purine biosynthesis pathway. Inhibitors of de novo purine biosynthesis induced selective killing of

104 MTAP-negative cells in culture ${ }^{27}$. One clinical trial on MPM using L-alanosine showed that this

105 inhibitor was ineffective at the dose used ${ }^{28}$. Further studies are necessary to conclude on the value of

106 this treatment strategy.

107 Genomic alteration studies have already contributed to our knowledge on the mechanisms of

108 mesothelial carcinogenesis, especially by identifying or confirming the involvement of tumor

109 suppressor genes (TSG) such as CDKN2A in MPM. They have also identified potential markers for

110 diagnosis, prognosis and treatment. New genes of interest could be identified by using technologies

111 providing more precise localization of altered chromosomal regions and, especially, by performing 
112 integrated mining of genomic data linked with epigenetic, miRNA profiling, and transcriptomic data

113 in the same cultured cells or primary tumors.

\section{2.2. DNA methylation}

115 Numerous genes have been shown to be downregulated in mesothelioma cells by epigenetic regulation

116 such as DNA methylation of their transcriptional promoters. These changes dysregulate several

117 signaling pathways, including the Wnt pathway, in which several negative regulators are silenced by

118 hypermethylation ${ }^{29-32}$. The global epigenetic profile determined by high-throughput methylation

119 analysis differs between MPM and normal pleura indicating that MPM, like other cancers, have

120 aberrant CpG island methylation ${ }^{33-34}$. Gene profiles of hypermethylation also differ between MPM

121 and other tumors ${ }^{33-37}$. These data support the hypothesis that a specific DNA methylation program is

122 induced during mesothelial carcinogenesis.

123 DNA methylation and clinicopathological features. DNA methylation of gene loci in MPM is

124 dependent on age, ethnic origin, histological subtype and asbestos exposure and could explain

125 discrepancies between the frequencies of DNA methylation in published studies as well as the

126 experimental method used to detect it. Age-dependent changes in DNA methylation have been

127 reported in the literature ${ }^{38}$. An age-associated increase of DNA methylation has been reported in

128 MPM patients ${ }^{39}$. The methylation status of the insulin growth factor binding protein IGFBP2 and

129 bone morphogenetic protein GDF10 loci has also been shown to be significantly higher in MPM from

130 Japanese patients than in USA patients ${ }^{40-41}$.

131 The frequencies of DNA methylation of TRAIL receptors (TNFRSF10C and TNFRSF10D) and tumor

132 suppressor RASSF1 have been reported to be significantly higher in epithelioid MPM than in

133 sarcomatoid MPM histological subtypes ${ }^{35,42}$. These data were not confirmed in another study for

134 RASSF1, but methylation of another gene, MT2A, encoding heavy metal binding protein was shown to

135 differ between these two histological subtypes ${ }^{43}$. High-throughput methylation analysis showed that

136 epithelioid and sarcomatoid mesotheliomas had differential methylation at $87 \mathrm{CpG}$ loci $^{44}$.

137 A significant association between asbestos exposure and DNA methylation at the MT1A, and MT2A

138 gene loci has also been described in MPM ${ }^{43}$. Methylation of TSG loci, APC, CCND2, CDKN2A,

139 CDKN2B, HPPBP1 and RASSF1 was studied in comparison with asbestos exposure. Only DNA 
140 methylation at the RASSF1 locus was correlated with an increased number of asbestos bodies in the

141 patient’s lung. A trend towards an increasing number of methylated cell cycle control genes and

142 increasing asbestos body counts was also observed ${ }^{39}$. Recently, high-throughput methylation analysis

143 confirmed distinct methylation profiles between MPM from asbestos-exposed and non-exposed

144 patients and a significant positive association between asbestos fiber burden and methylation status of

145 CDKN2A, CDKN2B, RASSF1 and MT1A in about one hundred other loci ${ }^{33}$.

146 DNA methylation and diagnosis. DNA methylation could be useful for the diagnosis of MPM.

147 Differences in the frequency of DNA methylation have been described for several genes between

148 MPM and lung adenocarcinoma or non-malignant pulmonary tissues ${ }^{35-36,43}$. High-throughput

149 methylation analysis covering several thousand $\mathrm{CpG}$ islands confirmed the potential value of DNA

150 methylation profile to distinguish MPM from these two other tissues. Accurate diagnosis could be

151 based on the global methylation profile, but further studies on larger populations are needed before

152 using a limited number of hypermethylated loci ${ }^{33-34,44}$. It was recently suggested that DNA

153 methylation at the three loci TMEM30B, KAZALD1 and MAPK13, could be useful in the differential

154 diagnosis of MPM ${ }^{34}$.

155 DNA methylation and patient outcome. DNA methylation status of individual genes such as the

156 transcriptional repressor HIC1, the pro-apoptotic protein PYCARD, the tumor suppressor LZTS1 and

157 the transporter SLC6A20 has been associated with either a good or poor prognosis ${ }^{43,45}$. High-

158 throughput methylation analysis showed that patients with MPM with a low frequency of DNA

159 methylation had a significantly longer survival ${ }^{34}$. Furthermore, classification based on the methylation

160 profile of patients undergoing surgical resection before any other treatment identified subgroups

161 characterized by different clinical outcomes ${ }^{33}$. These data highlight the potential prognostic value of

162 DNA methylation analysis.

163 In view of the aberrant epigenetic events observed in MPM, the clinical value of histone deacetylase

164 inhibitors (HDACi) has been studied in preclinical models using MPM cell lines and mouse xenograft

165 models. Phase I and II clinical trials in patients with MPM have been conducted using several different

166 HDACi, either alone or in combination with conventional chemotherapy. The encouraging results of 
167 these early-phase trials led to a phase III, multicenter, randomized, placebo-controlled study of one of

168 these HDACi in patients with advanced MPM ${ }^{46}$.

169 Like chromosome imbalance studies, epigenetic analyses identified genes or pathways potentially

170 involved in mesothelial carcinogenesis such as the Wnt pathway. At the present time, only the global

171 methylation profile appears to be relevant for diagnosis or to evaluate the patient's survival, thereby

172 limiting its clinical applications. Furthermore, epigenetic regulation mechanisms in MPM have been

173 mainly studied in terms of DNA methylation, but insufficient data are available on regulation of

174 histone modifications, despite their crucial role to maintain chromatin stability. Such data are

175 necessary to support clinical trials based on HDACi.

\section{2.3. miRNA expression}

177 Micro-RNAs (miRNAs) are emerging as key players in the control of a multitude of biological

178 processes and are aberrantly expressed in several tumors including MPM. MiRNA expression has

179 been shown to differ between MPM tumors and normal pleura ${ }^{47}$ and between MPM cell lines and

180 immortalized mesothelial cells ${ }^{48}$. MPM histological subtypes also demonstrate a specific miRNA

181 expression pattern ${ }^{47-48}$. Potential targets of these deregulated miRNAs include TSGs, oncogenes and

182 genes involved in specific signaling pathways ${ }^{47,49}$. However, a link between miRNA expression and

183 mesothelial carcinogenesis has been demonstrated by experimental analysis for only miR-31 and miR-

184 29c. MiR-31 is frequently lost in MPM due to its chromosomal location at 9p21.3, and miR-29c

185 expression is higher in epithelial MPM of patients with a good prognosis (time to progression greater

186 than one year). Overexpression induced by transfection of these two miRNAs decreased in vitro

187 proliferation, migration, invasion, and colony formation of the same two MPM cell lines ${ }^{50-51}$.

188 MiRNA and diagnosis. MiRNAs have been proposed as diagnostic tools. Downregulation of seven

189 miRNAs (miR-141, miR-200a, miR-200b, miR-200c, miR-203, miR-205 and miR-429) was shown to

190 be characteristic of MPM regardless of their histological subtypes, and could be used to distinguish

191 MPM from adenocarcinoma ${ }^{49}$. Another study demonstrated that the selection of three miRNAs (miR-

192 193, miR-200c and miR-192) could distinguish MPM from various carcinomas invading the lung and 193 pleura ${ }^{52}$. 
194 MiRNA and patient outcome. Some recent data suggest that miRNA expression could also be used as

195 prognostic tools, as downregulation of both miR-17 and miR-30c in sarcomatoid MPM and

196 upregulation of miR-29c in epithelioid MPM were significantly associated with better patient survival

$197 \quad 48,51$.

198 MiRNA expression analysis is a promising tool to improve the accuracy of diagnosis and could be

199 complementary to immunohistochemical markers. This analysis also opens up new perspectives for

200 the prognostic assessment of MPM in the near future. However, a better knowledge of miRNA

201 signatures of MPM is still necessary, as certain discrepancies have been observed between miRNA

202 profiling studies. Functional studies in cultured cells and animal models are also needed to determine

203 the precise contribution of miRNAs to mesothelial carcinogenesis and whether or not they can be used

204 as potential targets for anticancer therapy.

205

206 3. Molecular changes in malignant mesothelioma

207 3.1. Gene mutations

208 Knowledge of gene mutations provides insight into specific mechanistic pathways that can be altered

209 in MPM cells, opening the way for future targeted therapies. A number of genes are known to be

210 recurrently mutated in $\mathrm{MM}$.

211 TP53. The TP53 gene, a TSG located at 17p13.1 that controls cell cycle and apoptosis, is mutated in

212 many types of human cancers. Its mutation frequency is about $20 \%$ in human MPM, a fairly low rate

213 in comparison with other human cancers ${ }^{3}$. Point mutations are the main types of alterations in MM.

214 Six point mutations are indicated in the IARC p53 database, five missense mutations and one stop

215 mutation (http://p53.free.fr/Database/p53_database.html). In a study conducted to determine the

216 frequency of simian virus 40 (SV40) in Egyptian MM patients, altered p53 and pRb expressions were

217 found in $57.5 \%$ and $52.5 \%$ of patients, respectively, with no p53 mutation ${ }^{53}$. These authors assessed

218 the prognostic impact of altered expression of RB1 and TP53 gene status. Univariate analysis showed

219 a significant correlation between overall survival and p53 overexpression $(\mathrm{P}=0.05)$. Although

220 debated, SV40 has been associated with MM, and is assumed to act as a cofactor of asbestos in

221 carcinogenesis. In some MM, p53 protein function could be inactivated after binding to the Large T 
222 (Tag) SV40 protein, but SV40Tag expression in MM remains controversial ${ }^{54}$. In a recent study, no

223 expression of SV40-specific miRNA was detected in human malignant pleural mesothelioma (MM)

224 samples ${ }^{55}$.

225 No relationship has yet been established between TP53 mutation and clinical impact. The uncertainties

226 concerning p53 status in MPM appear to make it difficult to establish relationships between p53 status

227 and prognosis and/or treatment.

228 Neurofibromatosis 2 (NF2). The NF2 TSG, located on 22q12 was one of the first TSGs shown to be

229 inactivated in MPM ${ }^{56-57}$. Early conventional cytogenetic studies reported a loss of chromosome 22 in

230 human $\mathrm{MM}^{58-59}$. NF2 inactivation is frequent, with rates ranging from 20 to $60 \%$ depending on the

231 material used, tissue or cells, and the method (classical CGH, DNA sequencing...). Various types of

232 lesions have been described, including small and large deletions, homozygous deletions, nonsense and

233 missense mutations. The role of NF2 in mesothelial carcinogenesis will be described in the paragraph

234 on the hippo pathway.

235 INK4 locus. A second recurrent gene alteration occurring in human MM consists of inactivation of

236 genes located at the $C D K N 2 A$ locus. The $C D K N 2 A$ locus encodes both $\mathrm{p} 16^{\mathrm{INK} 4 \mathrm{~A}}$ and $\mathrm{p} 14^{\mathrm{ARF}}$ which

237 share common exons, but no common amino acid sequence. Alterations at this locus have been

238 demonstrated by DNA sequencing, FISH and methylation as reported above. The most frequent

239 alteration is homozygous deletion in about $70 \%$ of cases ${ }^{3}$. This alteration is related to asbestos

240 exposure in lung cancer and is also observed in mesotheliomas induced by mineral fibers in mice ${ }^{60-61}$.

241 The $C D K N 2 B$ gene adjacent to $C D K N 2 A$ is also frequently codeleted in MPM, but at a lower

242 frequency ${ }^{62}$.

243 FISH detection of $C D K N 2 A$ deletion has been proposed to differentiate between reactive and

244 malignant mesothelial cells on paraffin-embedded sections and effusion cytology ${ }^{19-20,63}$. Several

245 authors have reported that loss of the encoded protein $\mathrm{p} 16^{\mathrm{INK} 4 \mathrm{~A}}$, as assessed by immunohistochemistry

246 and FISH analyses confirmed by gene profiling microarray studies, is associated with lower survival

$247 \quad 25,64-67$.

248 CTNNB1. The beta-catenin status in MPM cells was reported in one study of 2 primary tumors and 8

249 cell lines in which one homozygous deletion was found in one cell line ${ }^{68}$. A modification of the 
250 subcellular localization of beta-catenin was reported in another study, consistent with activation of

251 beta-catenin as transcriptional cofactor ${ }^{69}$.

252 There is now a general consensus that several TSGs are frequently altered in MPM: NF2, CDKN2A,

$253 C D K N 2 B$, and, less frequently, TP53. In contrast, no recurrent oncogene mutation has yet been

254 identified in MPM.

\section{3.2. Gene expression profiling}

256 Data from array-based studies indicate deregulation of gene expression in MPM. These studies were

257 conducted in order to improve histological classifications and prognosis (Tables 3-5). These data were

258 recently reviewed by Gray et al. ${ }^{70}$.

259 Comparison with normal cells. Early studies were carried out with MPM cell lines compared to

260 normal pleural mesothelial cells (Table 3). Using a cDNA array including 588 genes : 26 genes that

261 play a role in signaling pathways (MAP3K14/NIK, a serine/threonine protein-kinase that stimulates

262 NF-kappaB activity; JAG1/JAGGED1 a ligand of the notch1 receptor), cell cycle (cyclin D1, CCND1;

263 cyclin D3, CCND3; CDK phosphatase, CDC25B), cell growth (fibroblast growth factor 3 and 12,

264 FGF3 and FGF12; platelet-derived growth factor receptor B, PDGFRB) and DNA damage repair

265 (XRCC5/Ku80) were overexpressed, and 13 genes encoding growth factors such as FGF1 and FGF7

266 (fibroblast growth factor 1 and 7), CCND2 (a regulatory subunit of cyclin-dependent kinases, involved

267 in cell cycle G1/S transition), KDR/VEGFR2 (vascular endothelial growth factor receptor 2), PDGFRA

268 (platelet-derived growth factor receptor), $R A R ß$ (retinoic acid receptor $ß 2$ ) and genes encoding

269 proteins involved in cell adhesion, motility and invasion were underexpressed ${ }^{71}$.

270 Differentially expressed genes were also related to tumor invasiveness and resistance to anticancer

271 defenses ${ }^{72}$. In another study, in a series of 14 differentially expressed genes, 8 were upregulated: $C F B$

272 (complement factor B), FTL (ferritin light polypeptide), IGFBP7 (insulin-like growth factor binding

273 protein 7), RARRES1 (retinoic acid receptor responder 1), RARRES2 (retinoic acid receptor responder

274 2), RBP1 (retinol-binding protein 1), SAT (spermidine/spermine N1-acetyltransferase) and TXN

275 (thioredoxin), while 6 were downregulated: ALOX5AP (arachidonate 5-lipoxygenase-activating

276 protein), CLNS1A (chloride channel nucleotide-sensitive 1A), EIF4A2 (eukaryotic translation 
initiation factor 4A2), ELK3 (ETS-domain protein, SRF accessory protein 2), DF2/REQ (apoptosis response zinc finger gene), and SYPL (synaptophysin-like protein) ${ }^{73}$.

279 The expression of 588 cancer-related genes was screened in 16 MPM tumors using normal mesothelial 280 cell lines and pleural mesothelium as references ${ }^{74}$. Eleven genes, COL1A2, COL6A1 (collagen), tPA, 281 MMP9 (protease), CDH3, L1CAM, ITGB4, PLXNA3/PLXN3, KRT14/K14 (cell adhesion or cell 282 surface molecule), SEMA3C (semaphorin), and CXCL10/INP10 (chemokine), were overexpressed in $283 \mathrm{MPM}^{74}$.

284 Microarray expression data of $40 \mathrm{MM}$ tumor specimens, 4 normal lung specimens and 5 normal pleura 285 specimens were reported by Gordon et al. ${ }^{75}$. These authors identified genes that were significantly 286 differentially expressed in tumors compared to normal samples. There were 328 overexpressed genes 287 and 311 underexpressed genes in MM tumors. These authors proposed 3 novel candidate oncogenes 288 NME2 (nucleoside diphosphate kinase), EID1/CRI1 (regulator of EP300 and RB1) and the PDGFC 289 (platelet-derived growth factor), and one candidate tumor suppressor GSN (cytoskeleton regulator) in $290 \mathrm{MPM}^{75}$.

291 In another study, MM tissue specimens from 16 patients were compared to 4 control pleural tissue 292 samples using cDNA microarray filters with 4132 clones ${ }^{76}$. Interestingly, upregulation of many genes 293 involved in the glycolysis pathway and the Krebs cycle was observed, in agreement with the ability of 294 cancer cells to rely on aerobic glycolysis, the "Warburg effect”. Other upregulated genes were 295 involved in mRNA translation and cytoskeletal reorganization pathways. These authors also identified 296 gp96 (adenotin, GRP94, HSP90B1), LRP (lung-related resistance protein, MVP), galectin-3 binding 297 protein (LGALS3BP) and Mr 67,000 laminin receptor (RPSA), but this last gene was not expressed on 298 tumor cells, but on infiltrating vessels.

299 More recently, Crispi et al. ${ }^{77}$ compared MPM tissues from 9 patients to normal pleural tissues from 300 patients undergoing resection for a non neoplastic disease. Components of the condensin complex 301 (e.g. BRRN1, CNAP1, NCAPD3) and members of the kinesin family (e.g. KIF14, KIF23, KIFC1) were

302 upregulated. Other upregulated genes were related to cell proliferation and its control such as cyclin303 dependent kinase $C D K 1 / C D C 2$, cyclin genes CCNA2, CCNB1, CCNB2 and CCNL2, the DLG7 
304 component of the mitotic apparatus, the checkpoint kinase involved in response to DNA damage

305 CHEK1/CHK1, and BUB1 and MAD2L1, components of the spindle checkpoint.

306 Romagnoli et al. ${ }^{78}$ used a quantitative polymerase chain reaction (PCR)-based, low-density array

307 focusing on genes involved in cell cycle regulation. They studied 45 MPM tumor samples and normal

308 tissue samples obtained by pleural wiping of surgical samples with no evidence of pleural disease.

309 Several genes were differentially expressed: either downregulated in cancer cells (UBE1L, CCND2),

310 or upregulated (CHEK1/CHK1, CCNH, CCNB1, p18-CDKN2C, CDC2, FOXM1, CDC6).

311 Overexpression of the cell cycle regulator Chk1 was confirmed in an independent set of $87 \mathrm{MM}$ by

312 immunohistochemistry using tissue microarrays. In another study, gene expression studies confirmed

313 by reverse transcriptase (RT)-PCR showed downregulation of the putative TSG FUS1/TUSC2 and the

314 cytokine OSM (oncostatin M) compared to normal samples (matched normal peritoneum specimens) ${ }^{\text {9, }}$

$315 \quad{ }^{79}$. Downregulation of FUS1/TUSC2 and PL6/TMEM115 was also observed in comparison with

316 matched normal pleura specimens ${ }^{9}$.

317 Features of malignant mesothelioma cells related to MM histology. Several studies have provided

318 data on MM classification (Table 4). A microarray transcriptional profiling study of 10 MPM cell

319 lines and 4 MPM primary tumor specimens distinguished epithelial, sarcomatoid and biphasic MPM.

320 Upregulated genes included ST14, a gene encoding matriptase, and a membrane serine protease

321 degrading the ECM, overexpressed in epithelial MPM ${ }^{80}$. In the comparative study with normal cells

322 quoted above, SEMA3C, ITGB4, CDH3 and COL6A1 were highly expressed in the epithelioid MPM

323 subtype, L1CAM, K14, INP10 were overexpressed in the mixed MPM subtype and MMP9 and PLXN3

324 were overexpressed in the sarcomatoid MPM subtype ${ }^{74}$. Statistically significant distinct gene

325 expression patterns between epithelial and non-epithelial tumors were reported to be correlated with

326 distinctive subclasses from hierarchical clustering in a series of $40 \mathrm{MPM}^{75}$. In a series of 99 tumors,

327 genes typical of epithelial differentiation, the cell-surface transmembrane proteins uroplakins 1B and

328 3B (UPK1B and UPK3B) and the protease kallikrein 11 (KLK11) were more highly expressed in

329 epithelioid $\mathrm{MM}^{25}$. Romagnoli et al. ${ }^{78}$ compared epithelioid and nonepithelioid MPM using a

330 quantitative PCR-based low-density array. Two genes were overexpressed in epithelioid MPM, the

331 transcription factor TFDP2 and the protooncogene ABL1, whereas the transcription factor TWIST1 
was overexpressed in the nonepithelioid group. In an attempt to classify genes according to their correlation with survival, more favorable genes were associated with epithelioid morphology and unfavorable genes were associated with sarcomatoid type or epithelioid MM with poor outcome ${ }^{25}$. Features of malignant mesothelioma cells related to the outcome of MM patients. Other authors have tried to improve prognostic assessment by using gene expression analyses (transcriptome and/or quantitative RT-PCR) of MM primary tumors or cell lines (Table 5). In a study investigating mesothelioma surgical specimens, calculation of three gene expression ratios, KIAA0977/GDIA1, L6/CTHBP, and L6/GDIA1 was found to be a good predictor of surgical treatment-related outcome. Samples with geometric means greater than 1 and less than 1 were assigned to good-outcome and poor-outcome groups, respectively ${ }^{81}$. In a cohort of 39 patients undergoing surgery, these authors validated previous findings and identified new sets of gene expression ratios CD9/KIAA1199, CD9/THBD, DLG5/KIAA1199, and DLG5/THBD allowing classification of tumors according to patient outcome ${ }^{82}$. In a more recent study, Gordon et al. ${ }^{83}$ investigated 120 consecutive patients with malignant pleural mesothelioma treated by surgery. None of the patients had received preoperative neoadjuvant chemotherapy or radiation therapy. By analyzing data for four genes, they defined three ratios of gene expression (TM4SF1/PKM2, TM4SF1/ARHDDIA, COBLL1/ARHDDIA), which, associated with other prognostic factors, were able to discriminate high-risk and low-risk patients. A cohort of 1,153 samples from patients diagnosed with 11 distinct types of cancer including 17 patients with mesothelioma from the study by Gordon et al. ${ }^{81}$ was investigated by microarray analysis, looking for molecular signatures based on the polycomb group BMI-1-associated gene expression pathway, a pathway essential for self-renewal of hematopoietic and neural stem cells ${ }^{84}$. Expression of the 11-gene signature was a powerful predictor of poor prognosis in cancer patients. These 11 genes were Gbx2, KI67, CCNB1, BUB1, KNTC2, USP22, HCFC1, RNF2, ANK3, FGFR2, and $C E S 1^{84}$.

Several studies have identified specific genes associated with patient outcome. In a study comparing MM samples from patients with short-term recurrence after surgery (STR) and patients with longer time to relapse (LTR), the cadherin $C D H 2$ was upregulated especially in the STR group. In contrast, 
the chaperone protein DNAJA1 showed reduced expression in the STR cohort. In addition, the authors noted no discrimination between epithelial and biphasic histological types ${ }^{9}$.

361 Aurora kinases A and B (AURKA and $A U R K B)$ are serine/threonine kinases that play an important role in chromosome alignment, segregation and cytokinesis during mitosis. They were found to be

363 overexpressed in a study of $99 \mathrm{MPM}^{25}$. The expression of aurora kinases and genes participating in

364 cell division and mitotic control was further investigated in $29 \mathrm{MPM}^{85}$. Expressions of AURKA and

$365 A U R K B$ and related genes were correlated, and overexpression of AURKB determined by

366 immunohistochemistry was significantly correlated with poor outcome ${ }^{85}$.

367 A correlation between metalloproteinase MMP14 expression and overall survival was reported in one

368 study of 9 patients with MPM treated by standard thoracotomy for therapeutic purposes compared to 4 normal pleural samples ${ }^{77}$. High MMP14 expression was associated with lower survival. This gene has been proposed as a potential MPM biomarker. Upregulation of MELK (maternal embryonic leucine zipper kinase) was associated with poor survival, confirming previous findings by Lopez-Rios et al. ${ }^{25}$,

372 but BTG2, which plays a role in regulation of G1/S transition, was associated with different outcomes

373 in these 2 studies. Other genes, BIRC5 an inhibitor of apoptosis, KIF4A an ATP-dependent

374 microtubule-based motor protein and SEPT9, a member of the septin family involved in cytokinesis

375 and cell cycle control, were upregulated and associated with poor prognosis ${ }^{77}$. In this study, a

376 favorable survival was associated with downregulation of transcription factor WT1 in contrast with a

377 previous study, which associated long-term survival with upregulation of $W T 1^{25}$.

378 Microarray analysis discriminated between normal and MM samples in a comparative study of 8 normal peritoneum and 7 stage I MM, subsequently validated on a large set of matched normal/MM samples by RT-PCR. Intense overexpression of HAPLN1 (hyaluronan and proteoglycan link protein

381 1), a protein of the extracellular matrix (ECM), was observed in MM samples. Immunostaining with 382 anti-HAPLN1 antibodies demonstrated that all MPM types (epithelial, mixed, and sarcomatoid) as

383 well as reactive mesothelium expressed this gene. Moreover, HAPLN1 expression was negatively

384 correlated with time to progression and survival ${ }^{86}$. Functional studies using transfection assays revealed that MM cells overexpressing full-length HAPLN1 or its functional domains strongly

386 supported the protumorigenic role of HAPLN1. 
387 A meta-analysis was carried out on published data on microarray analysis of gene expression profiles

388 in mesothelioma, glioma and prostate cancer ${ }^{87}$. Mesothelioma data were derived from the study by

389 Gordon et al. ${ }^{81}$. MM cases consisted of eight good responders who survived more than 17 months,

390 while 10 patients in the poor responder group survived less than 6 months. A list of genes generated

391 according to patient outcome showed similarities between the three types of cancers ${ }^{87}$. Thirteen highly

392 expressed genes and one gene expressed at low levels were identified as being equally related to poor

393 survival in the 3 types of cancers. These genes encode proteins of the ECM and regulators of ECM

394 assembly, and angiogenesis genes ${ }^{87}$. These results are consistent with a more aggressive state of

395 malignant cells, and a more deleterious tumor microenvironment. These results may be of interest for

396 combining tumor-specific and more global therapies.

397 An analysis of 6 MPM compared to normal visceral and parietal pleural tissues has focused on

398 differential gene expression and identification of pathways that could be related to the drug and

399 irradiation resistance of pleural $\mathrm{MM}^{88}$. Several genes encoding proteins known to control DNA

400 replication, cell cycle regulation and DNA repair were identified as over- or underexpressed in MPM

401 could account for MPM resistance mechanism to chemotherapies ${ }^{88}$.

402 These studies show changes in the expression of genes involved in several regulatory pathways.

403 Discrimination between epithelioid and non-epithelioid MPM was reported in several studies without

404 apparent benefit for classification of MPM subtypes in comparison with classical histological analysis.

405 Other studies developed a gene ratio approach to predict outcome in patients having undergone

406 surgery. No extrapolation can be made to other therapeutic settings, such as chemotherapy, can be

407 made at the present time. Several specific genes were identified as potential predictors of patient

408 outcome. Although providing a number of candidate areas to kill cancer cells or abolish their growth,

409 these results need to be confirmed on a larger number of cases before proceeding to clinical

410 applications. An important issue is to determine the most pertinent individual approach in relation to

411 the various biological features of MM cells.

\section{3.3. Pathway regulation}

413 Receptor tyrosine kinases. Membrane receptor tyrosine kinases (RTKs) drive downstream cell

414 signaling to cell proliferation and cell cycle control, survival and differentiation ${ }^{89}$. Downstream 
415 networks from RTKs can be activated by RTK mutation or sustained signaling by autocrine or

416 paracrine mechanisms, providing a useful context to therapeutically counter the effects of RTK

417 activation.

418 Epidermal growth factor receptor (EGFR) is generally not mutated in human MPM. However, in an

419 immunohistochemical study, EGFR was expressed in 44\% of MPM cases ${ }^{90}$. EGFR protein status was

420 statistically significantly associated with a favorable prognosis, but was not an independent prognostic

421 factor, when compared to clinicopathological status ${ }^{90}$. A tissue array study was performed on

422 epithelioid tissue samples from 48 MPM cases for comparison between long-term survival and short-

423 term survival, associated with the expression of other proteins involved in the corresponding pathway

$424{ }^{91}$. A relationship was found between EGFR expression and long-term survival, whereas PDGFR

425 signaling was more strongly associated with short-term survival ${ }^{91}$. In contrast, no relationship was

426 found between survival and EGFR protein or mRNA expression ${ }^{92}$.

427 EGFR alteration cannot be considered to be critical in MPM at the present time, which could explain

428 why, although high EGFR expression is found in MPM, EGFR inhibitors, gefitinib and erlotinib, did

429 not induce any significant tumor response when applied in phase II studies in patients with MPM ${ }^{93}$.

430 Response rates were situated between 0 and $4 \%$ and median overall survival was between 4.6 and

$431 \quad 13.1$ months in phase II trials including patients with either first-line chemotherapy failure or no

432 previous treatment ${ }^{94-96}$.

$433 \underline{K I T / C D 117}$ encodes a stem cell factor receptor. In MPM, KIT expression has mostly been studied by

434 immunohistochemistry, showing a low percentage of positive tumors ${ }^{97}$. No expression was detected

435 by RT-PCR in a study of 37 MPM ${ }^{98}$. KIT has not been shown to be characteristic of MPM at the

436 present time.

437 Vascular endothelial growth factor receptors (VEGFRs). Several immunohistochemical studies

438 demonstrated an enhanced expression of vascular endothelial growth factor (VEGF) in a large

439 proportion of MPM in comparison with non neoplastic specimens ${ }^{99}$. Contradictory results were found

440 regarding the correlation between VEGF expression and survival. VEGF was not identified as a

441 prognostic factor in studies of 52 and 37 MPM specimens, respectively ${ }^{100-101}$. In contrast, in a study of

44240 MPM tissues, VEGF showed significant correlation with short survival, and was an independent 
443 prognostic factor ${ }^{102}$. MPM cells express both VEGF and VEGFRs (fms-related tyrosine kinases, FLT1 444 and FLT4) and fetal liver kinase (KDR/FLK1) ${ }^{103-106}$. An autocrine role of VEGF has been suggested, 445 using neutralizing antibodies against VEGF or the VEGFR, or antisense oligonucleotides against 446 VEGF that significantly reduced MM cellular proliferation ${ }^{105,107}$. VEGF expression can be regulated 447 by lipoxygenases. Human MPM cells, but not normal mesothelial cells, express a catalytically active 448 5-LO (arachidonate 5-lipoxygenase). A 5-LO antisense oligonucleotide potently and time-dependently 449 reduced VEGF mRNA and constitutive VEGF accumulation in the conditioned media of MPM cells $450{ }^{108}$. These results indicate that VEGF may have multiple effects, as a key regulator of MM growth via 451 activation of its tyrosine kinase receptors, and as promoter of tumor angiogenesis.

452 Despite unsuccessful early trials of anti-VEGF therapy, numerous clinical trials are testing the benefit 453 of VEGF inhibitors in combination with chemotherapy ${ }^{95,109}$.

$454 \quad$ Platelet-derived growth factor receptors (PDGFRs). MM cell growth may be linked to autocrine or 455 paracrine stimulation by platelet-derived growth factor (PDGF), and the regulation by PDGF appears 456 to be complex in MM cells. Normal human mesothelial cells express low levels of PDGF-A mRNA 457 chain and the PDGF-B mRNA was not detectable ${ }^{110}$. These cells express PDGFR-A mRNA and 458 protein and had weak to undetectable levels of the PDGFR-B mRNA and protein ${ }^{111}$. In contrast, 459 human MM cells express high level of PDGF-A and PDGF-B, as well as PDGFR-B ${ }^{110-111}$. However, 460 expression of PDGFR-B is controversial and weak to undetectable levels were reported ${ }^{110-113}$. 461 Nevertheless, an autocrine proliferation can be suggested in MM, as it may occur via binding of 462 homodimer of PDGF-B chains ${ }^{114}$. PDGF has been suggested as a regulatory factor for proliferation of 463 MM cells, either directly, or indirectly via the hyaluronan/CD44 pathway. Hyaluronan is an important 464 constituent of the extracellular matrix. PDGF-BB-stimulated normal human mesothelial cells express 465 both hyaluronan synthase and hyaluronan ${ }^{115-116}$.

466 PDGF-A-stimulated autocrine loop does not seem to play a positive role in mesothelioma proliferation 467 in vitro, but nude mice injected with MM cells that over-express PDGF-A showed increased tumor 468 incidence and reduced latency period to tumor formation ${ }^{117-118}$. These data suggest that PDGF-A 469 could contribute to tumor formation via a paracrine mechanism to generate favorable environmental 470 conditions, e.g. by stimulating angiogenesis, for tumor proliferation ${ }^{118}$. 
471 Like EGFR targeted therapy, the PDGFRs inhibitor, imatinib mesylate, was ineffective in clinical

472 trials ${ }^{119-120}$.

473 Insulin growth factor receptors (IGFRs). Human MM cells express IGF and IGFR ${ }^{121}$. IGF-I appears to 474 function as an autocrine growth stimulus in human mesothelial cells ${ }^{122}$. When activated, IGFR

475 phosphorylates multiple classes of signal transduction adaptators, including insulin receptor substrates

476 (IRS). IRS-1 was found to induce cell proliferation in response to IGF-1, whereas cell migration was

477 induced by IRS-2 ${ }^{123}$. In addition, various members of the insulin-like growth factor binding protein

478 (IGFBP) family have been investigated in MPM. IGFBPs form a complex with IGFR subunit and IGF, 479 and have been shown to either inhibit or stimulate the growth promoting effect of IGF. IGFBPs can be 480 either expressed or unexpressed in MM, modulating the aggressiveness of the MM phenotype ${ }^{121,124-}$ $481 \quad 125$.

482 Hepatocyte growth factor receptor (MET) is a proto-oncogene. Mutation in the MET gene appears to 483 be uncommon in MPM. No mutation was reported in a study of 20 cell lines ${ }^{126}$, but 5 point mutations 484 and one deletion were identified in a series of 43 primary tumors and 7 cell lines ${ }^{127}$. The encoded 485 protein is involved in pathways regulating development, cell growth and survival, motility and 486 invasion. It is expressed in most MPM and in reactive mesothelium but not in normal mesothelial cells $487{ }^{128-129}$. Hepatocyte growth factor/Scattering factor (HGF/SF), the related Met ligand, is also expressed 488 in some but not all MPM cells. In vitro stimulation of MPM cells by HGF/SF increased spreading, 489 motility and/or invasiveness, but these effects were dependent on the cell line ${ }^{127,130-131}$. Experimental 490 studies with cultured MPM cells demonstrated that inhibition of MET by RNA interference or protein 491 kinase inhibitor resulted in G1/S arrest and reduction of the activity of Akt and Erk1/2 signaling in 492 some cell lines ${ }^{127,131}$. However, no correlation was found between levels of MET and ERK1/2 493 phosphorylation ${ }^{126}$. In the light of these results showing a tumor-dependent activation of HGF/MET 494 signaling, HGF/MET status could define various MPM subclasses.

495 The activation status of MET and other RTKs, EGFR family (Erb1, Erb2, Erb3), PDGF-A and 496 PDGFR-B was investigated in 20 MPM cell lines and 23 primary specimens of MPM, and the effect 497 of MET-specific inhibitors (MET-shRNA interference vector and RTK inhibitors) was investigated on 
cell lines ${ }^{126}$. The results showed that inhibition of single RTK was not sufficient to obtain a tumor suppressor effect but that inhibition of multiple RTK should be considered ${ }^{126}$.

MAPK. As several RTK receptors are tyrosine-phosphorylated in some MM, downstream activation of the MAPK (mitogen-activated protein kinase) proliferation-associated signaling pathway is likely. Several studies have investigated phosphorylation of proteins of the MAPK cascade, extracellularregulated kinases (ERKs), Jun amino-terminal kinases/stress-activated kinases (JNKs/SAPKs), and p38 MAPK. Other studies have tried to modulate MAPK pathways in order to inhibit cell survival and induce apoptosis.

Phospho-ERK expression was studied by immunohistochemistry in 50 biopsy specimens including non-small-cell lung cancer and normal lung, and pleural tissue comprising 10 MPM (6 epithelioid, 1 sarcomatoid and 3 biphasic) ${ }^{132}$. MPM showed significant ERK phosphorylation compared to lung cancer and normal tissues ${ }^{132}$. Activation of ERK, JNK, and p38 MAPK was investigated in 28 MPM and 8 peritoneal MM (32 effusions and 4 biopsies) and 14 samples of reactive mesothelium by assessing the expression of phosphorylated proteins by immunohistochemistry and western blot. MAPK activation did not differentiate between benign and malignant mesothelial cells ${ }^{133}$. The authors argued against a major role for this pathway in the malignant transformation of mesothelial cells. They also noted that MAPK expression and phosphorylation were better predictive factors of outcome, in agreement with data obtained in ovarian cancer ${ }^{133}$. Arsenic trioxide $\left(\mathrm{As}_{2} \mathrm{O}_{3}\right)$ is a chemical compound that has been reported to inhibit cell proliferation and induce apoptosis in tumor cells via the MAPK pathways. $\mathrm{As}_{2} \mathrm{O}_{3}$ inhibited proliferation and induced apoptosis in one mesothelioma cell line ${ }^{134}$. $\mathrm{As}_{2} \mathrm{O}_{3}$ did not alter phosphorylation of either Akt or Src, while ERK1/2 and JNK1/2, but not p38 MAPK, were markedly phosphorylated after $\mathrm{As}_{2} \mathrm{O}_{3}$ treatment, indicating the involvement of the JNKdependent ERK-dependent pathway in the cell response ${ }^{134}$. However, p38 MAPK appears to be involved in the response to TGF-beta. In 6 human MM cell lines, migration and invasion linked to the production of metalloproteinases were stimulated by TGF-beta1 via phosphorylation of p38 MAP kinase. The authors suggested that this pathway could be targeted to reduce mesothelioma progression ${ }^{113}$. Ou et al. ${ }^{135}$ determined the relative levels of tyrosine phosphorylation of 42 distinct RTKs in 
526 mesothelioma cell lines established from surgical specimens and found coordinated activation of

527 RTKs EGFR, ERBB3, AXL and MET. As MAPK can be activated by heat shock proteins (HSP),

528 these authors studied the effect of HSP90 inhibition on ERK1/2 activation. HSP90 inhibition reduced

529 TKs phosphorylation and induced apoptosis ${ }^{135}$. The effect of other HSPs was also investigated in the

530 context of the possible use of hyperthermic chemotherapy ${ }^{136}$. HSP40 was upregulated in response to

531 heat stress, associated with activation of the ERK1/2 and p38 pathways in a study of 3 MPM cell lines,

532 suggesting that treatment could be more effective by blocking these pathways ${ }^{136}$. HSP90

533 overexpression has been reported in MPM ${ }^{88}$, and DNAJA1, a member of the HSP40 family, showed

534 decreased expression in MPM with short-term recurrence of the disease ${ }^{9}$.

535 These results show that regulation of mesothelioma cells via MAPK pathways is complex. Targeting

536 these pathways to abolish cell proliferation could be proposed, but the treatment strategy would be

537 difficult to define at the present time. MAPK activation is important for cell survival and can also be

538 linked to apoptosis events. More specific investigations taking into account specific tumor

539 characteristics and microenvironment must be conducted in order to trigger cell growth inhibition and

540 apoptosis.

541 PI3K/AKT. Constitutive activation of RTKs in MM results in downstream signaling cascades

542 including phosphatidylinositol-3-kinase (PI3K-AKT), a cascade regulating cell growth processes, cell

543 migration and apoptosis. Phosphorylation of AKT protein, the active form of the protein, has been

544 demonstrated in MM cells. Immunohistochemical analysis revealed elevated levels of phospho-AKT

545 in nearly two-thirds of human primary MPM. A strong association with elevated phospho-mTOR

546 positivity in the same tumors confirmed activation of the Akt pathway ${ }^{137}$. Activation of AKT triggers

547 anti-apoptotic mechanisms. However, while the PI3K-Akt signaling pathway was activated in

548 adherent MPM cells, loss of anchorage resulted in inactivation of this pathway and failed to restore

549 apoptosis ${ }^{138}$. Inactivation of PTEN (phosphatase and tensin homolog deleted from chromosome 10), a

550 TSG and negative regulator of the PI3K-AKT pathway, could account for PI3K-AKT activation.

551 PTEN homozygous deletion has been reported in a small subset of MPM cell lines ${ }^{139-140}$. A tissue

552 microarray-based study carried out on 206 tumor tissues demonstrated that loss of PTEN expression

553 was observed in $62 \%$ of cases ${ }^{141}$. In this study, PTEN expression was correlated with better survival 
554 from data available in 129 patients. PTEN was an independent prognostic biomarker in mesothelioma 555 patients ${ }^{141}$

556 Wnt pathway. The Wnt signaling pathway regulates developmental processes, cell proliferation and 557 cell polarity. It is driven by membrane protein activation involving low-density lipoprotein receptor558 related protein (LRP) and Frizzled, and G-protein-coupled receptors. Activation of the Wnt signaling 559 pathway prevents beta-catenin phosphorylation and its subsequent ubiquitination and degradation.

560 Beta-catenin plays a central role in the Wnt pathway activity, as beta-catenin can act as a coactivator

561 of transcription, allowing the expression of a variety of genes exerting pleiotropic effects ${ }^{142}$. While no 562 recurrent mutation of beta-catenin has been described in MPM, the Wnt pathway could be altered as a 563 result of promoter hypermethylation of regulatory genes ${ }^{29,31-32}$. Apart from this canonical Wnt/beta-

564 catenin pathway, a non-canonical beta-catenin-independent Wnt pathway can also transduce signals in 565 MPM cells. This was demonstrated in beta-catenin-deficient MPM cells, in which inhibition of Wnt 566 signaling produced growth reduction and apoptosis ${ }^{30,143}$.

567 Gene expression profiling of MM cell lines, primary MPM tumors and normal pleural tissue has been 568 studied by using a custom array designed to profile the expression of genes involved in the Wnt 569 signaling pathway and downstream to Wnt signaling ${ }^{144}$. In the sixteen matched samples (malignant 570 tissue and normal adjacent pleura) investigated, numerous Wnt genes (WNT1, WNT2, WNT5) and 571 Wnt-related genes (MYC, CCND1, JUN) were upregulated. WNT2 was most frequently upregulated. 572 In contrast, WNT8A and some WNT antagonists (DKK1, SFRP2 and SFRP4) were downregulated. A 573 role of WNT2 in cell survival was demonstrated using anti-Wnt2 antibody and Wnt2 siRNA, 574 associated with inhibition of the downstream effectors of the Wnt pathway ${ }^{144}$. Wnt signaling 575 inhibition is dependent on several factors including the Dickkopf ( $D K K)$ gene family. One member, 576 REIC/Dickkopf-3, is downregulated in numerous human cancers ${ }^{145}$. In four human MM cell lines, 577 REIC/Dickkopf-3 expression was lower than in normal tissue, and overexpression by transduction in 578 one cell line induced apoptosis via a JNK-dependent pathway ${ }^{145}$. Moreover, a preclinical study 579 consisting of orthotopic inoculation of REIC/Dickkopf-3-deficient luciferase-labeled MM cells 580 followed by intrapleural injection of recombinant REIC/Dickkopf-3-adenovirus resulted in a strong 581 antitumor effect ${ }^{145}$. These results suggest that deregulation of the Wnt signaling pathway can be 
582 involved in mesothelial carcinogenesis, and that identification of key targets could be of interest to 583 suppress tumor development.

584 Hippo pathway. Merlin, the protein encoded by NF2, regulates cell growth by signaling via the Hippo 585 pathway to inhibit the function of the transcriptional coactivator and candidate oncogene YAP1 via its 586 phosphorylation. Overexpression of YAP1 was found in one MM cell line ${ }^{146}$. Moreover, Yap1 protein 587 physically and functionally interacted with merlin and, in NF2-transfected cells, merlin expression 588 reduced the nuclear localization of Yap1, suggesting that merlin can inhibit Yap1 function by 589 sequestration ${ }^{146}$. Inactivating homozygous deletions or mutations of LATS2 were recently 590 demonstrated by CGH and DNA sequencing analyses in about 22\% of MPM including 20 cell lines 591 and 25 primary tumors ${ }^{147}$. Disruption of NF2 signaling plays a major role in the development of MPM 592 in view of the high rate of mutations in this tumor. Despite a wild-type status of $N F 2$, the merlin also 593 appears to be present in an inactivated phosphorylated form in MPM cells ${ }^{148}$. Recent data suggest that 594 the Hippo pathway involving the merlin could be targeted for treatment strategies. There is now a 595 general consensus concerning inactivation of the Hippo pathway in MPM. To the best of our 596 knowledge, NF2 expression has not been associated with any specific MPM subtype or specific 597 characteristics and has not been linked to prognosis. Investigation of merlin function in MPM could be 598 useful to develop new therapies. Some examples have been published in the literature. Using NF2599 negative MM cell lines transduced with a recombinant NF2 Adenovirus (AdNF2), cDNA microarray 600 analyses revealed differences in gene expression profiles characterized by a decrease in cyclin D1 601 (CCND1) expression, a gene upregulated in MPM, in cells transduced with AdNF2 compared to those 602 transduced with the control adenovirus. In parallel, CDK4, the catalytic partner of cyclin D1, was 603 inactivated and pRb was dephosphorylated, in agreement with efficient control of the G1/S transition 604 in NF2-expressing cells. G1 cell cycle arrest was confirmed by cell cycle analysis ${ }^{149}$. In this study, the 605 authors found that the effect of NF2 was related to repression of cyclin-D1 promoter activity via 606 PAK1 inhibition ${ }^{149}$. NF2 function could also be related to regulation of motility and invasiveness in 607 MM cells, as demonstrated by downregulation of focal adhesion kinase (FAK), and inhibition of 608 motility and invasiveness following NF2-transfection and overexpression of FAK in 2 NF2-deficient 609 mesothelioma cell lines ${ }^{150}$. A relationship between NF2 expression and apoptosis in MM cells has 
610 been reported in other studies. In a study on the role of integrin-specific signaling in the control of

611 apoptosis factors, NF2 was demonstrated to have an inactivating role on integrin-dependent mTORC1

612 signaling ${ }^{151}$. In this study, eleven MM cell lines were analyzed, four not expressing merlin and 7

613 expressing merlin, for their activity in mTORC1, ERK, and AKT. While activation of ERK or AKT

614 was not correlated with the loss of merlin or activation of mTORC1, inactivation of merlin promoted

615 mTORC1 signaling independently of AKT or ERK ${ }^{151}$.

616 Ubiquitin-proteasome. Differences of the expression of genes involved in the ubiquitin/proteasome

617 pathway have been observed between MM and normal tissue or according to histological subtype.

618 Several genes encoding proteasome complex subunits were upregulated in MPM tumors compared to

619 normal parietal pleura ${ }^{88}$. Others proteins involved in the ubiquitin/proteasome pathway, such as the

620 FAS-associated factor FAF1 which inhibits protein degradation of ubiquitinylated proteins, were

621 recurrently altered at the genomic level in MM of p19 ${ }^{\text {ARF }}$ (+/-) mice and were downregulated in human

$622 \mathrm{MM}^{152-153}$. In peritoneal MM, several genes involved in the ubiquitin-proteasome pathway were

623 upregulated in biphasic tumors compared to epithelioid tumors ${ }^{154}$. In pleural MM, subunits of the

624 proteasome complex (PSME3, PSMA3 and PSMA4) and ubiquitin-conjugating enzyme (UBE2S) were

625 upregulated in the epithelioid phenotype variant compared to the sarcomatoid phenotype variant of the

626 same MPM cell lines ${ }^{155}$.

627 Several studies have analyzed the impact of proteasome inhibitors on MPM malignancy in preclinical

628 models. Bortezomib (PS-341 or Velcade ${ }^{\circledR}$ ), a specific inhibitor of 20S proteasome activity, induces in

629 vitro apoptosis and in vivo tumor growth inhibition in mice of one MPM cell line ${ }^{156}$. Other

630 proteasome inhibitors, PSI or MG-132, were also shown to induce apoptosis in some MPM cell lines

$631 \quad{ }^{157-158}$. Using MPM cell lines in monolayer culture, bortezomib was shown to increase the cytotoxicity

632 of chemotherapeutic agents ${ }^{159}$. However, MM cell lines, when grown as multicellular spheroids,

633 acquired resistance to apoptosis induced by a combination of the proteasome inhibitor MG-132 and

634 other apoptotic stimuli ${ }^{160}$. Results of ongoing phase II clinical trials using bortezomib combined with

635 cisplatin will indicate the efficacy of proteasome inhibitors in the management of MM

636 (ClinicalTrials.gov Identifier: NCT00458913).

\section{Cell cycle regulation.}


638 Alteration of genes located at the INK4 locus, encompassing CDKN2A and CDKN2B, is a feature of

639 human MM. Inactivation of these genes allows uncontrolled cell proliferation. While some MM do not

640 show mutation or methylation of these genes, another level of regulation could occur via deregulation

641 of miRNA expression (see above, chapter 2.3). Several authors have developed experimental studies

642 trying to restore cell cycle control in MM by adenovirus-mediated expression of $\mathrm{p} 16^{\mathrm{INK} 4 \mathrm{~A}}$ and $\mathrm{p} 14^{\mathrm{ARF}}$

643 in human MM cells, and found effects on both cell cycle progression and reduction of tumor growth in

644 immunocompromised mice ${ }^{161-163}$.

645 Cell cycle control can be affected in MM cells by the loss of other negative regulators, CDK (cyclin-

646 dependent kinases) inhibitors or by the overexpression of CDKs and cyclins (CCNs), and regulators of

647 the mitotic checkpoints ${ }^{85,88}$. The expression profile of 60 genes involved in cell cycle has been

648 investigated in forty-five MM tumor samples and normal pleural tissue ${ }^{78}$. Among genes

649 overexpressed in MM, several were involved in cell cycle checkpoints such as CDK1/CDC2 (cyclin-

650 dependent kinase 1), CDC6 (cell division cycle 6, a regulator of replication), CDKN2C (cyclin-

651 dependent kinase inhibitor 2C, p18), CCNH (cyclin H), CCNB1 (cyclin B1, controling the cell cycle

652 at the G2/M transition), CHEK1 (Chk1 is required for checkpoint-mediated cell cycle arrest in

653 response to DNA damage) and FOXM1 (forkhead transcription factor, a regulator of gene expression

654 in the G2 phase). In contrast, CCND2 (cyclin D2, a regulator of Cdk4 and Cdk6, controls the cell

655 cycle at the G1/S transition) was underexpressed ${ }^{78}$. Aurora kinases are involved in microtubule

656 formation and are important regulators of the mitotic spindle checkpoint system, controlling

657 progression of mitosis until all chromosomes are properly aligned during metaphase. An

658 overexpression of aurora kinases has been reported in different studies ${ }^{25,85}$. Aurora B levels increase

659 after gamma irradiation, and MM cells arrest at the G2/M checkpoint of the cell cycle to repair DNA

660 damage before proceeding through mitosis ${ }^{164}$. Stathmin is also important for the evolution of mitosis

661 as it is involved in the regulation of the microtubule dynamics, by inhibiting the formation of

662 microtubules and/or promoting their depolymerization. Kim et al. ${ }^{165}$ identified potential genes

663 involved in pathogenesis of MPM. They investigated seven MM cell lines, fresh mesothelioma tissues

664 and adjacent normal pleural tissues using cDNA microarray chips. Multiple genes were overexpressed

665 in MM cell lines compared to the human mesothelial cell strain LP-9 derived from the ascitic fluid of 
666

667

668

669

670

671

672

673

674

675

676

677

678

679

680

681

682

683

684

685

686

687

688

689

690

691

692

693 a patient with an ovarian carcinoma, and stathmin was one of the most strongly overexpressed genes ${ }^{165-166}$. Protein expression of stathmin was observed in MPM tissues but not in matched normal pleural samples ${ }^{165}$.

Because of these different alterations, response to DNA damage can be impaired in MPM cells entailing chromosomal instability. Well-controlled cell cycle progression is necessary for cells to respond to both endogenous and exogenous DNA damage. Although MPM cell cycle may be arrested in response to DNA damaging agents, it may be assumed that MPM cells recover, likely due to their inability to trigger the apoptotic mechanism. Moreover, a heterogeneity exists between different tumors. After exposure to gamma-radiation, human MPM cells were arrested either in one or more phases of the cell cycle, demonstrating a heterogeneity in cell cycle control. G1 arrest was p21WAF1/CIP1- and p53-dependent ${ }^{167}$. As mentioned in chapter 3.1 p53 can be inactivated in MPM, and its inactivation will facilitate chromosomal instability, in relation to loss of cell cycle control, especially in response to DNA damage. Regulation of p53 function occurs via post-translational mechanisms and interaction with several protein. MDM4 was recently shown to control p53 function in a human MM cell line ${ }^{168}$.

Overall, these studies demonstrate that cell cycle dysregulation occurs in all phases, at the level of checkpoint control and related factors, encouraging the search for stimulation of death pathways in MPM cells.

Apoptosis. Malignant MM responds poorly to standard therapy ${ }^{169}$. Mesothelioma tissue usually has a lower apoptotic index than other carcinomas ${ }^{170}$, suggesting major defects in the apoptotic machinery. Apoptosis is mediated by two signaling pathways, the extrinsic and intrinsic pathways. The extrinsic pathway is initiated by death receptors, while the intrinsic pathway is triggered by internal apoptotic signals and involves the release of cytochrome c from the mitochondrial intermembrane space. These two pathways merge and share mechanisms of the caspase cascades ${ }^{171}$. In the extrinsic pathway, the death receptor agonist TRAIL can induce apoptosis with a high specificity toward tumor cells and is currently being tested in clinical trials in a variety of human cancers. In mesothelioma, TRAIL has been to shown to enhance the chemosensitivity of tumor cells to various therapeutic agents, such as doxorubicin, gemcitabine, cis-platinum or etoposide. However, most MM cells are resistant to 
694 apoptosis induced by TRAIL alone ${ }^{172}$. This resistance can be explained notably by overexpression of

695 the caspase-8 inhibitor, FLIP/CFLAR, and by the methylation of TRAIL receptors in MM cells ${ }^{173}$.

696 Several multimodal approaches have subsequently been applied to sensitize MM cells to TRAIL. Heat

697 stress, as well as subtoxic doses of alpha-tocopheryl succinate or anisomycin can sensitize MM cells

698 to TRAIL and induce apoptosis in vitro, via Bid-dependent mitochondrial amplification of the

699 apoptotic signal ${ }^{174-176}$. Inversely, the multikinase inhibitor sorafenib showed synergistic effects with

700 TRAIL in cells resistant to TRAIL, independently of caspase activation ${ }^{177}$. Interestingly, in contrast

701 with mesothelioma cell monolayers, tumor fragment spheroids exhibit higher resistance to apoptosis

702 and notably to TRAIL-combined treatments, and this resistance is mediated by the mTor/S6K pathway

$703 \quad 160,178$. In the intrinsic pathway, the mitochondrial membrane potential and permeability are regulated

704 by the Bcl-2 family of proteins. Members of this family include both proapoptotic proteins such as

705 Bax, Bak, Bad, Bid or Bim, and antiapoptotic proteins, such as Bcl-2, Bcl-xL and Mcl-1. Bcl-2 is

706 rarely expressed in mesothelioma ${ }^{170}$, while high levels of Bcl-xL are commonly observed ${ }^{179}$. Several

707 studies have shown that downregulation of Bcl-xL could decrease baseline tumor cell viability and

708 improve sensitivity to chemotherapeutic agents, both in vitro and in vivo ${ }^{180-182}$. Mcl-1 has also been

709 implicated in the apoptotic resistance of mesothelioma cells ${ }^{158,179}$. Recently, Varin et al. showed that

710 Bcl-xL and Mcl-1 cooperated to protect mesothelioma cells from cell death and that their concomitant

711 targeting was sufficient to induce apoptosis ${ }^{183}$. Most members of the proapoptotic Bcl-2 family appear

712 to be expressed in mesothelioma with functional integrity, suggesting that the loss of their apoptosis-

713 inducing properties is due to sequestration by Bcl-xL or Mcl- ${ }^{184}$. In particular, functional inhibition

714 of Bim contributes to survival in the spheroid model of mesothelioma cells ${ }^{138}$.

715 The inhibitor of apoptosis protein (IAP) survivin, encoded by the BIRC5 gene, was highly expressed

716 in all MM primary tumors (12 samples) and cell lines (7/8) compared with normal pleura ${ }^{185}$. Survivin

717 expression in $34 \mathrm{MM}$ tumors was confirmed by immunohistochemistry and linked to an apoptotic

718 defect ${ }^{170}$. Downregulation of survivin with anti-survivin oligonucleotides induced apoptosis when

719 tested in one cell line ${ }^{185}$. Inhibition of survivin expression has been shown to decrease tumor cell

720 growth and enhance drug response ${ }^{186}$. XIAP is also frequently expressed in malignant mesothelioma,

721 and is notably upregulated in mesothelioma effusions and peritoneal mesothelioma ${ }^{187}$. Moreover, 
722

723

724

725

726

727

728

729

730

731

732

733

734

735

736

737

738

739

740

741

742

743

744

745

746

747

748

749

XIAP inhibition has been shown to increase the sensitivity of mesothelioma cells to TRAIL-induced apoptosis ${ }^{188}$. Together, these results suggest that combined approaches, triggering the extrinsic and intrinsic pathways or the caspase cascade, are promising for the treatment of mesothelioma.

Telomere. Human telomeres progressively shorten during cell division, and critical shortening is believed to limit the cellular life span, and is involved in conferring growth-promoting properties to tumor cells. Telomere lengthening is due to telomerase (TERT) activity, which was found in a large proportion of the 22 primary pleural MM and the $4 \mathrm{MM}$ cell lines in comparison with mesothelial cells from normal pleura using the telomeric repeat amplification protocol (TRAP) ${ }^{189}$. These findings were confirmed in a more recent study carried out in peritoneal MM and another mechanism, alternative lengthening of telomeres, was also demonstrated to maintain telomere length ${ }^{190}$. Interestingly, in their series of $44 \mathrm{MM}$ peritoneal lesions from 38 patients, these authors found that telomerase activity was a significant prognostic factor for 4-year relapse and disease-free survival. Telomerase activity was reduced in MM cell lines in comparison with normal cells by inhibition of MetAP2 (methionine aminopeptidase) with angiostatic agents fumagillin and ovalicin. This enzyme is overexpressed, in MM cells ${ }^{191}$.

\section{Conclusions}

Molecular studies have identified somatic genetic and epigenetic alterations in MPM cells, associated with altered expression, activation or inactivation of critical genes in oncogenesis. Deregulation of signaling pathways related to differentiation, survival, proliferation, apoptosis, cell cycle control, metabolism, migration and invasion has been demonstrated in complementary studies. These changes were found by investigating individual gene status in genomic and transcriptomic studies, and were supported by immunohistological studies. MPM cells show a large spectrum of abnormalities shared with other malignancies, or more specific alterations such as those of the NF2 gene. Comparative studies of series of MPM have usually demonstrated that both alterations in a given gene and combined genetic and epigenetic alterations are present in MPM subsets, consistent with inter- 
individual variations of molecular alterations. There are therefore at least two levels of heterogeneity, at the genome level and at the gene level, suggesting that identification of patient subgroups would be essential in order to develop more specific therapies. Moreover, the tumor microenvironment, consisting of a large number of different cell types, adds another level of complexity to identify the best strategy to improve the outcome of this disease. This tumor heterogeneity could explain differences in patient survival and response to treatments.

This review provides insight into a limited number of genes known to be frequently altered in MPM, INK4 locus and NF2, and a larger number of candidates that may play a role in MPM carcinogenesis, especially those involved in various signaling pathways. Further studies should define the clustering of these genes in specific MPM subsets. These findings have already been the basis for several studies testing various targeted therapeutic approaches on specific RTKs, but mostly with limited success. Demonstration of the multiple alterations present in the tumor should encourage research into combined or more global therapies. Other studies have emphasized deregulation of signaling pathways, but no pathway seems to be specific or a particularly relevant target, as certain discrepancies have been observed concerning the response of MPM cells to specific inhibitors, and key regulatory players in one pathway may interact with another pathway. Focusing on apoptosis is probably an interesting strategy to counteract or trigger the activity of several of these pathways. More recent data have indicated the presence of alterations that could be targeted at a global level (methylation). Studies are ongoing to take advantage of these abnormalities for MPM treatment. Prediction of a positive response in MPM would avoid a rapidly unfavorable course and avoid wasting time and resources with inappropriate treatments. The critical issue concerning targeted therapy is to focus on the most relevant target(s). Some molecules, pathways and/or epigenetic changes should be selected, provided they are key factors in MPM. This is not an easy task regarding the interplay between the various regulatory pathways, and the diversity of genomic alterations. Molecular studies must be developed to identify and classify genomic alterations in MPM cells and correlate these alterations with disease outcome in order to avoid random testing of therapies already used in other cancers, but with unknown relevance in MPM. In recent years, several studies have been designed to evaluate the predictive role of microarray data for MM outcome. Various authors have developed 
778 predictors of survival, but in some studies the accuracy was lower than that of prognosis based on the

779

780

781

782

783

784

785

786

787

788

789

790

791

792

793

794

795

796

797

798

799

800

801

802

803

804 usual methods comprising clinicopathological variables and morphology. Other authors have proposed innovative predictors based on gene expression ratios. These procedures are of great interest and deserve further validation.

Our improved understanding of MPM development and treatment is partly based on well designed preclinical studies. Numerous in vitro investigations are currently underway to suppress MPM cell growth and/or induce apoptosis by interacting with proteins regulating proliferation and survival, or by silence gene expression (RNA interference). These methods benefit from the data provided by molecular analyses providing preclinical proof of concept for the feasibility of such strategies.

However, these studies were carried out in MPM specimens that do not necessarily present the same genomic status as the tumors of patients selected for the relevant therapy. In the context of preclinical investigations, animal models must be combined with studies prior to translation to humans. An important point to be emphasized here is the paramount importance of frozen and paraffin MPM tissue banks to allow better characterization and annotation of MPM, as well as panels for diagnostic certification. Databases and panels are already available, such as the Mesothelioma Virtual Bank (http://www.mesotissue.org) ${ }^{192}$ or the International Mesothelioma Excellence Center (IM@EC).

Over recent years, considerable methodological progress has been made in the field of molecular approaches to study cancer biology and this progress has been applied to MPM. Improvements are still in progress. Other methodologies have not yet been applied to MPM, such as proteomics, cell imaging, integrative biology and will likely be useful in the future, in order to identify MPM biomarkers, exposure markers and MPM subgroups.

Various clinical studies have shown that future treatment strategies must not be based on monotherapy, but must comprise multi-site and multimodal treatment. As this disease is particularly aggressive, it requires a specific treatment strategy. Investigation of the tumor genome and related pathophysiological events has therefore become a key step to a better understanding and possible cure of this dreadful incurable cancer. 
Table 1. Genomic and epigenetic changes of potential interest for MPM histology, diagnosis and prognosis.

\begin{tabular}{|c|c|c|}
\hline Genes & Significance & Reference \\
\hline \multicolumn{3}{|l|}{ Diagnosis } \\
\hline Chromosomal alteration & $\begin{array}{l}\text { Frequency different between MPM and lung } \\
\text { carcinoma and others splindle tumors of the } \\
\text { pleura }\end{array}$ & $21-22$ \\
\hline $\begin{array}{l}\text { DNA methylation status of } \\
\text { specific gene loci }\end{array}$ & $\begin{array}{l}\text { Frequency different between MPM and lung } \\
\text { adenocarcinoma and non-malignant pulmonary } \\
\text { tissue }\end{array}$ & 33-36, 43-44 \\
\hline MiRNA expression level & $\begin{array}{l}\text { Difference between MPM and lung } \\
\text { adenocarcinoma }\end{array}$ & 49 \\
\hline MiRNA expression level & $\begin{array}{l}\text { Difference between MPM and various } \\
\text { carcinoma }\end{array}$ & 52 \\
\hline \multicolumn{3}{|l|}{ Histology } \\
\hline Chromosomal alteration & $\begin{array}{l}\text { Frequency different between epithelioid and } \\
\text { sarcomatoid MPM }\end{array}$ & 6 \\
\hline $\begin{array}{l}\text { DNA methylation status of } \\
\text { specific gene loci }\end{array}$ & $\begin{array}{l}\text { Frequency different between between } \\
\text { epithelioid and sarcomatoid MPM }\end{array}$ & $35,42-44$ \\
\hline \multicolumn{3}{|l|}{ Prognosis } \\
\hline $\begin{array}{l}\text { Chromosomes and } \\
\text { chromosome } 7 \mathrm{p}\end{array}$ & $\begin{array}{l}\text { Inverse correlation between copy number and } \\
\text { survival }\end{array}$ & 16,23 \\
\hline $\begin{array}{l}\text { CDKN2A locus (9p21.3) } \\
\text { homozygous deletion }\end{array}$ & $\begin{array}{l}\text { Correlation with shorter survival or shorter } \\
\text { time to relapse }\end{array}$ & 9,25 \\
\hline $\begin{array}{l}\text { Number of chromosomal } \\
\text { alteration }\end{array}$ & Correlation with shorter time to relapse & 9 \\
\hline $\begin{array}{l}\text { Number of chromosomal } \\
\text { region loss }\end{array}$ & $\begin{array}{l}\text { Correlation with shorter survival in deciduoid } \\
\text { MPM }\end{array}$ & 26 \\
\hline $\begin{array}{l}\text { DNA methylation status of } \\
\text { HIC1, PYCARD, LZTS1 } \\
\text { and SLC6A20 gene loci }\end{array}$ & Potential association with survival & 43,45 \\
\hline $\begin{array}{l}\text { Occurence of DNA } \\
\text { methylation }\end{array}$ & $\begin{array}{l}\text { Correlation between low frequency and longer } \\
\text { survival }\end{array}$ & 34 \\
\hline DNA methylation profile & $\begin{array}{l}\text { Prognostic prediction depending of specific } \\
\text { profiles }\end{array}$ & 33 \\
\hline MiR-17 and mIR-30c & $\begin{array}{l}\text { Correlation between reduced expression and } \\
\text { better survival in sarcomatoid MPM }\end{array}$ & 48 \\
\hline MiR-29c & $\begin{array}{l}\text { Correlation between increased expression and } \\
\text { better survival in epithelioid MPM }\end{array}$ & 51 \\
\hline
\end{tabular}


Table 2. Recurrent regions of chromosomal alterations in MPM.

\begin{tabular}{|c|c|c|c|c|c|c|c|}
\hline Alteration & $\begin{array}{c}\text { CGH } \\
\text { (90 tumors) }{ }^{6}\end{array}$ & $\begin{array}{c}\text { CGH array } \\
{\text { (17 tumors })^{7}}^{7}\end{array}$ & $\begin{array}{c}\text { CGH array } \\
\text { (26 tumors) }{ }^{8}\end{array}$ & $\begin{array}{c}\text { ROMA } \\
\text { (22 tumors) }^{9}\end{array}$ & $\begin{array}{c}\text { SNP array } \\
(23 \text { tumors) }\end{array}$ & \begin{tabular}{|c|} 
SNP array \\
$(22$ cultured cells $)$
\end{tabular} & $\begin{array}{c}\text { CGH array } \\
\text { (33 cultured cells ) }\end{array}$ \\
\hline \multirow[t]{9}{*}{ Gain } & 1q23-q32 (16\%) & $1 q(44 \%)$ & & & 1q23 (35\%) 1q32 (22\%) & & \\
\hline & & $5 p(44 \%)$ & & 5p14 (55\%) & $5 p(22 \%)$ & & 5p15.3-p11 (51\%) \\
\hline & 7p14-p15 (14\%) & $7 p(44 \%)$ & & & 7p14-p15 (22\%) & & 7p22-p11.2 (37\%) \\
\hline & 8q22-q23 (18\%) & $8 q 24(56 \%)$ & & 8q23-q24 (36\%) & $\begin{array}{c}8 q 22-q 23(20 \%) \\
8 q 24(22 \%)\end{array}$ & & \\
\hline & 15q22-q25 (14\%) & & & & $15 q 22-q 25(17 \%)$ & & \\
\hline & & & 17q21.32-q25 (27\%) & 17q21-q23 (24\%) & & $17 q 23.2(55 \%)$ & \\
\hline & & & & $18 q 12.1(36 \%)$ & & & \\
\hline & & 20p (33\%) & & & 20p (9\%) & & \\
\hline & & & & & & & 20q11.2-q13.1 (34\%) \\
\hline \multirow[t]{22}{*}{ Loss } & & $\begin{array}{c}\text { 1p36.33 (11\%) } \\
\text { 1p36.1 (33\%) }\end{array}$ & & $\begin{array}{l}\text { 1p36.22-p36.23 (36\%) } \\
\text { 1p36.11-p36.12 (55\%) }\end{array}$ & $\begin{array}{c}\text { 1p36.1 (30\%) } \\
\text { 1p36.33 (39\%) }\end{array}$ & 1p36.3-p36.2 (55\%) & 1p36.3-p35 (51\%) \\
\hline & 1p21 (21\%) & 1p21.3 (56\%) & 1p31.1-p13.2 (42\%) & 1p13.2-p13.3 (36\%) & 1p21.3 (30\%) & 1p22.3-p22.1 (82\%) & 1p31-p12 (40\%) \\
\hline & 3p21 (16\%) & 3p21.3 (33\%) & 3p22.1-p14.2 (42\%) & $\begin{array}{c}\text { 3p21.31 (27\%) } \\
\text { 3p14.3-p14.2 (32\%) }\end{array}$ & 3p21.3 (44\%) & 3p22.1-p21.31 (77\%) & 3p23-p14 (63\%) \\
\hline & $\begin{array}{l}\text { 4q31-q32 (29\%) } \\
\text { 4p12-p13 (25\%) }\end{array}$ & $\begin{array}{c}\text { 4q22 (56\%) } \\
\text { 4q34-q35.2 (33\%) }\end{array}$ & & & $\begin{array}{c}\text { 4p12 (26\%) 4q22 (30\%) } \\
\text { 4q31-q32 (35\%) }\end{array}$ & Chr4 (53\%) & Chr4 (54\%) \\
\hline & $6 q 22(16 \%)$ & $6 q 25(44 \%)$ & $6 q 22.1(58 \%)$ & & $6 q 22(26 \%) 6 q 25(39 \%)$ & & 6q14-q27 (57\%) \\
\hline & & & & & & & 8p23-p12 (31\%) \\
\hline & 9p21 (34\%) & 9p21.3 (100\%) & 9p21.3 (65\%) & $\begin{array}{l}\text { 9p21.3 (32\%) } \\
\text { 9p21.1 (36\%) }\end{array}$ & 9p21 (39\%) & 9p21.3 (100\%) & 9p24-q21 (91\%) \\
\hline & & & & 9q34.11 (41\%) & & & \\
\hline & 10p13-p15 (16\%) & 10p (44\%) & & & 10p13 (9\%) & & 10p15-p12 (37\%) \\
\hline & & & & & & & 10q23-q26 (37\%) \\
\hline & & & & & & 11q23.2-q23.3 (64\%) & \\
\hline & & & & & & & 12p13 (54\%) \\
\hline & 13q13-q14 (19\%) & $13 q 33.2(44 \%)$ & 13q11-q14.12 (35\%) & & 13q13-14 (17\%) & 13q12.2-q13.2 (73\%) & $13 q(60 \%)$ \\
\hline & 14q12-q24 (23\%) & & & & 14q12-q24 (22\%) & & 14q11.2-q21 (40\%) \\
\hline & & $14 q 32.13(56 \%)$ & 14q22.1-32 (38\%) & & $14 q 32.13(17 \%)$ & $14 q 32.2(73 \%)$ & $14 q 24-q 32(40 \%)$ \\
\hline & & & & & & $15 q 15.1(55 \%)$ & $15 q 13-q 21(40 \%)$ \\
\hline & 17p13-p12 (16\%) & & & 17p13.1 (46\%) & 17p12 (17\%) & & 17p13-p11.2 (34\%) \\
\hline & & & & 17q21.31 (32\%) & & & \\
\hline & & $18 q(33 \%)$ & & & $18 q(13 \%)$ & $18 q 12.3(59 \%)$ & 18q12-q23 (46\%) \\
\hline & & & & 19p13.2 (55\%) & & & 19p13.1-p12 (31\%) \\
\hline & & & & 19q13.32 (55\%) & & & 19q13.2-q13.4 (31\%) \\
\hline & $22 q(32 \%)$ & $22 q(33 \%)$ & 22q11-q12.3 (35\%) & $22 \mathrm{q} 12.2(74 \%)$ & $22 q(43 \%)$ & Chr22 (78\%) & $22 q(80 \%)$ \\
\hline
\end{tabular}


Page 33 / 
813

814

\begin{tabular}{lc}
\hline Genes & Reference \\
\hline Overexpressed in comparison with normal cells & \\
\hline MAP3K14/NIK, JAG1/JAGGED1, CCND1, CCND3, CDC25B, & 71 \\
FGF3, FGF12, PDGFRB, XRCC5/Ku80 & 72 \\
\hline CFB, FTL, IGFBP7, RARRES1, RARRES2, RBP1, SAT, TXN & 74 \\
\hline COL1A2, COL6A1, tPA, MMP9, CDH3, L1CAM, ITGB4, & 76 \\
PLXNA3/PLXN3, KRT14/K14, SEMA3C, CXCL10/INP10 & 76 \\
\hline Genes involved in glycolysis & 77 \\
\hline HSP90B1, LRP, LGALS3BP & 77 \\
\hline Members of the condensin complex and of the kinesin family & 78 \\
\hline CDK1/CDC2, CCNA2, CCNB1, CCNB2, CCNL2, DLG7, & 71 CHEK1/CHK1, BUB1, MAD2L1 \\
\hline CHEK1/CHK1, CCNH, CCNB1, p18-CDKN2C, CDC2, FOXM1, & 71 \\
\hline UDC6 & 72 \\
\hline FGF1, FGF7, CCND2, KDR/VEGFR2, RARß & 78 \\
\hline ALOX5AP, CLNS1A, EIF4A2, ELK3, DF2/REQ, SYPL & 97 \\
\hline UBE1L, CCND2 & 79 \\
\hline FUS1/TUSC2, OSM, PL6/TMEM115 & 76 \\
\hline
\end{tabular}

Table 3. Genes of potential interest for MPM characterization

815

816 
817 Table 4. Genes of potential interest for characterization of MPM subtypes

818

\begin{tabular}{|c|c|c|}
\hline Genes & Significance & Reference \\
\hline \multicolumn{3}{|l|}{ Histology } \\
\hline ST14 & $\begin{array}{l}\text { Overexpressed in epithelial MM in comparison } \\
\text { with sarcomatoid and biphasic MM }\end{array}$ & 80 \\
\hline $\begin{array}{l}\text { SEMA3C, ITGB4, CDH3, } \\
\text { COL6A1 }\end{array}$ & $\begin{array}{l}\text { Overexpressed in epithelioid MM in comparison } \\
\text { with normal cells }\end{array}$ & 74 \\
\hline L1CAM, K14, INP10 & $\begin{array}{l}\text { Overexpressed in biphasic MM in comparison } \\
\text { with normal cells }\end{array}$ & 74 \\
\hline MMP9, PLXN3 & $\begin{array}{l}\text { Overexpressed in sarcomatoid MM in comparison } \\
\text { with normal cells }\end{array}$ & 74 \\
\hline UPK1B, UPKЗB, KLK11 & $\begin{array}{l}\text { Overexpressed in epithelioid vs non epithlioid } \\
\text { MM }\end{array}$ & 25 \\
\hline TFDP2, ABL1 & $\begin{array}{l}\text { Overexpressed in epithelioid vs non epithlioid } \\
\text { MM }\end{array}$ & 78 \\
\hline TWIST11 & $\begin{array}{l}\text { Overexpressed in non epithelioid vs epithlioid } \\
\text { MM }\end{array}$ & 78 \\
\hline
\end{tabular}

819

820

821 
822

\begin{tabular}{|c|c|c|}
\hline Genes & Significance & Reference \\
\hline \multicolumn{3}{|l|}{ Patients' outcome } \\
\hline$P 16 / C D K N 2 A$ & $\begin{array}{l}\text { Gene loss or no protein } \\
\text { expression associated with low } \\
\text { survival }\end{array}$ & $25,64-67$ \\
\hline $\begin{array}{l}\text { KIAA0977/GDIA1, L6/CTHBP, } \\
\text { L6/GDIA1 }\end{array}$ & Gene ratios predict outcome & 81 \\
\hline $\begin{array}{l}\text { CD9/KIAA1199, CD9/THBD, } \\
\text { DLG5/KIAA1199, DLG5/THBD }\end{array}$ & Gene ratios predict outcome & 82 \\
\hline $\begin{array}{l}\text { TM4SF1/PKM2 } \\
\text { TM4SF1/ARHDDIA } \\
\text { COBLL1/ARHDDIA }\end{array}$ & $\begin{array}{l}\text { Gene ratio discriminate high risk } \\
\text { and low risk patients }\end{array}$ & 83 \\
\hline $\begin{array}{l}\text { Gbx2, KI67, CCNB1, BUB1, } \\
\text { KNTC2, USP22, HCFC1, } \\
\text { RNF2, ANK3, FGFR2, CES1 }\end{array}$ & $\begin{array}{l}\text { Expression associated with poor } \\
\text { prognostic }\end{array}$ & 84 \\
\hline $\mathrm{CDH} 2$ & $\begin{array}{l}\text { Overexpressed in the short-term } \\
\text { recurrence group }\end{array}$ & 9 \\
\hline DNAJA1 & $\begin{array}{l}\text { Underexpressed in the short-term } \\
\text { recurrence group }\end{array}$ & 9 \\
\hline AURKA, AURKB & $\begin{array}{l}\text { Expression associated with poor } \\
\text { outcome }\end{array}$ & 85 \\
\hline MELK & $\begin{array}{l}\text { Upregulation associated with } \\
\text { poor survival }\end{array}$ & 25 \\
\hline BIRC5, KIF4A, SEPT9 & $\begin{array}{l}\text { Upregulation associated with } \\
\text { poor prognosis }\end{array}$ & 77 \\
\hline HAPLN1 & $\begin{array}{l}\text { Expression negatively correlated } \\
\text { with survival }\end{array}$ & 86 \\
\hline DNAJA1 & $\begin{array}{l}\text { Underexpressed in the short-term } \\
\text { recurrence group }\end{array}$ & 9 \\
\hline MMP14 & $\begin{array}{l}\text { High expression associated with } \\
\text { lower survival }\end{array}$ & 77 \\
\hline LELK1 & $\begin{array}{l}\text { Upregulation associated with } \\
\text { poor survival survival }\end{array}$ & 25 \\
\hline $\begin{array}{l}\text { Thirteen genes involved in } \\
\text { ECM, regulators of ECM } \\
\text { assembly, angiogenesis }\end{array}$ & $\begin{array}{l}\text { High expression associated with } \\
\text { poor survival }\end{array}$ & 87 \\
\hline
\end{tabular}

Table 5. Genes of potential interest for MPM characterization and predictive prognostic value 
Bibliography

830

831

832

1. Sandberg AA, Bridge JA. Updates on the cytogenetics and molecular genetics

of bone and soft tissue tumors. Mesothelioma. Cancer Genet Cytogenet. 2001;127(2):93-110.

834

2. Musti M, Kettunen E, Dragonieri S et al. Cytogenetic and molecular genetic

changes in malignant mesothelioma. Cancer Genet Cytogenet. 2006;170(1):9-15.

3. Sekido Y. Genomic abnormalities and signal transduction dysregulation in malignant mesothelioma cells. Cancer Sci. 2010;101(1):1-6.

4. Gibas Z, Li FP, Antman KH, Bernal S, Stahel R, Sandberg AA. Chromosome changes in malignant mesothelioma. Cancer Genet Cytogenet. 1986;20(3-4):191-201. malignant mesothelioma. Cancer Genet Cytogenet. 1990;47(1):1-28. differences between histological subtypes of malignant mesotheliomas: DNA cytometry and comparative genomic hybridization of 90 cases. J Pathol. 2002;197(3):363-371. in malignant pleural mesothelioma using oligonucleotide array CGH. Cytogenet Genome Res. 2007;119(1-2):46-52. mesothelioma with array-based comparative genomic hybridization shows frequent non850 random chromosomal alteration regions including JUN amplification on 1p32. Cancer Sci. 2007;98(3):438-446. 
10. Cheung M, Pei J, Pei Y, Jhanwar SC, Pass HI, Testa JR. The promyelocytic

855 leukemia zinc-finger gene, PLZF, is frequently downregulated in malignant mesothelioma

856 cells and contributes to cell survival. Oncogene. 2010;29(11):1633-1640.

857 11. Christensen BC, Houseman EA, Poage GM et al. Integrated profiling reveals a 858 global correlation between epigenetic and genetic alterations in mesothelioma. Cancer Res. 859 2010;70(14):5686-5694.

860 12. Jean D, Thomas E, Manie E et al. Syntenic Relationships between Genomic 861 Profiles of Fiber-Induced Murine and Human Malignant Mesothelioma. Am J Pathol. $862 \quad$ 2011;178(2):881-894.

863 13. Bueno R, De Rienzo A, Dong L et al. Second generation sequencing of the 864 mesothelioma tumor genome. PLoS One. 2010;5(5):e10612.

865 14. Lechner JF, Tokiwa T, LaVeck M et al. Asbestos-associated chromosomal 866 changes in human mesothelial cells. Proc Natl Acad Sci U S A. 1985;82(11):3884-3888.

867 15. Jaurand MC, Renier A, Daubriac J. Mesothelioma: Do asbestos and carbon 868 nanotubes pose the same health risk? Part Fibre Toxicol. 2009;6:16.

869 16. Tiainen M, Tammilehto L, Rautonen J, Tuomi T, Mattson K, Knuutila S. 870 Chromosomal abnormalities and their correlations with asbestos exposure and survival in 871 patients with mesothelioma. Br J Cancer. 1989;60(4):618-626.

872 17. Tammilehto L, Tuomi T, Tiainen M et al. Malignant mesothelioma: clinical 873 characteristics, asbestos mineralogy and chromosomal abnormalities of 41 patients. Eur $J$

874 Cancer. 1992;28A(8-9):1373-1379.

875 18. Illei PB, Ladanyi M, Rusch VW, Zakowski MF. The use of CDKN2A deletion 876 as a diagnostic marker for malignant mesothelioma in body cavity effusions. Cancer. $877 \quad 2003 ; 99(1): 51-56$. 
19. Savic S, Franco N, Grilli B et al. Fluorescence in situ hybridization in the 879 definitive diagnosis of malignant mesothelioma in effusion cytology. Chest. 2010;138(1):137-

880

881

882

883

884

885

886

887

888

889

890

891

892

893

894

895

896

897

898

899

900

901 144.

20. Chung CT, Santos Gda C, Hwang DM et al. FISH assay development for the detection of p16/CDKN2A deletion in malignant pleural mesothelioma. J Clin Pathol. 2010;63(7):630-634.

21. Bjorkqvist AM, Tammilehto L, Nordling S et al. Comparison of DNA copy number changes in malignant mesothelioma, adenocarcinoma and large-cell anaplastic carcinoma of the lung. Br J Cancer. 1998;77(2):260-269.

22. Knuuttila A, Jee KJ, Taskinen E, Wolff H, Knuutila S, Anttila S. Spindle cell tumours of the pleura: a clinical, histological and comparative genomic hybridization analysis of 14 cases. Virchows Arch. 2006;448(2):135-141.

23. Tiainen M, Rautonen J, Pyrhonen S, Tammilehto L, Mattson K, Knuutila S.

Chromosome number correlates with survival in patients with malignant pleural mesothelioma. Cancer Genet Cytogenet. 1992;62(1):21-24.

24. Illei PB, Rusch VW, Zakowski MF, Ladanyi M. Homozygous deletion of CDKN2A and codeletion of the methylthioadenosine phosphorylase gene in the majority of pleural mesotheliomas. Clin Cancer Res. 2003;9(6):2108-2113.

25. Lopez-Rios F, Chuai S, Flores R et al. Global gene expression profiling of pleural mesotheliomas: overexpression of aurora kinases and P16/CDKN2A deletion as prognostic factors and critical evaluation of microarray-based prognostic prediction. Cancer Res. 2006;66(6):2970-2979.

26. Scattone A, Pennella A, Gentile M et al. Comparative genomic hybridisation in malignant deciduoid mesothelioma. J Clin Pathol. 2006;59(7):764-769. 
902

903

904

905

906

907

908

909

910

911

912

913

914

915

916

917

918

919

920

921

922

923

924

27. Kamatani N, Nelson-Rees WA, Carson DA. Selective killing of human malignant cell lines deficient in methylthioadenosine phosphorylase, a purine metabolic enzyme. Proc Natl Acad Sci U S A. 1981;78(2):1219-1223.

28. Kindler HL, Burris HA, 3rd, Sandler AB, Oliff IA. A phase II multicenter study of L-alanosine, a potent inhibitor of adenine biosynthesis, in patients with MTAPdeficient cancer. Invest New Drugs. 2009;27(1):75-81.

29. Lee AY, He B, You L et al. Expression of the secreted frizzled-related protein gene family is downregulated in human mesothelioma. Oncogene. 2004;23(39):6672-6676.

30. He B, Lee AY, Dadfarmay S et al. Secreted frizzled-related protein 4 is silenced by hypermethylation and induces apoptosis in beta-catenin-deficient human mesothelioma cells. Cancer Res. 2005;65(3):743-748.

31. Batra S, Shi Y, Kuchenbecker KM et al. Wnt inhibitory factor-1, a Wnt antagonist, is silenced by promoter hypermethylation in malignant pleural mesothelioma. Biochem Biophys Res Commun. 2006;342(4):1228-1232.

32. Kohno H, Amatya VJ, Takeshima Y et al. Aberrant promoter methylation of WIF-1 and SFRP1, 2, 4 genes in mesothelioma. Oncol Rep. 2010;24(2):423-431.

33. Christensen BC, Houseman EA, Godleski JJ et al. Epigenetic profiles distinguish pleural mesothelioma from normal pleura and predict lung asbestos burden and clinical outcome. Cancer Res. 2009;69(1):227-234.

34. Goto Y, Shinjo K, Kondo Y et al. Epigenetic profiles distinguish malignant pleural mesothelioma from lung adenocarcinoma. Cancer Res. 2009;69(23):9073-9082.

35. Toyooka S, Pass HI, Shivapurkar $\mathrm{N}$ et al. Aberrant methylation and simian virus 40 tag sequences in malignant mesothelioma. Cancer Res. 2001;61(15):5727-5730. 
36. Tsou JA, Shen LY, Siegmund KD et al. Distinct DNA methylation profiles in

926

927

928

929

930

931

932

933

934

935

936

937

938

939

940

941

942

943

944

945

946

947

malignant mesothelioma, lung adenocarcinoma, and non-tumor lung. Lung Cancer. 2005;47(2):193-204.

37. Marsit CJ, Houseman EA, Christensen BC et al. Examination of a CpG island methylator phenotype and implications of methylation profiles in solid tumors. Cancer Res. 2006;66(21):10621-10629.

38. Richardson B. Impact of aging on DNA methylation. Ageing Res Rev. 2003;2(3):245-261.

39. Christensen BC, Godleski JJ, Marsit CJ et al. Asbestos exposure predicts cell cycle control gene promoter methylation in pleural mesothelioma. Carcinogenesis. 2008;29(8):1555-1559.

40. Tomii K, Tsukuda K, Toyooka S et al. Aberrant promoter methylation of insulin-like growth factor binding protein-3 gene in human cancers. Int J Cancer. 2007;120(3):566-573.

41. Kimura K, Toyooka S, Tsukuda K et al. The aberrant promoter methylation of BMP3b and BMP6 in malignant pleural mesotheliomas. Oncol Rep. 2008;20(5):1265-1268.

42. Shivapurkar N, Toyooka S, Toyooka KO et al. Aberrant methylation of trail decoy receptor genes is frequent in multiple tumor types. Int J Cancer. 2004;109(5):786-792. 43. Tsou JA, Galler JS, Wali A et al. DNA methylation profile of 28 potential marker loci in malignant mesothelioma. Lung Cancer. 2007;58(2):220-230.

44. Christensen BC, Marsit CJ, Houseman EA et al. Differentiation of lung adenocarcinoma, pleural mesothelioma, and nonmalignant pulmonary tissues using DNA methylation profiles. Cancer Res. 2009;69(15):6315-6321. 
45. Suzuki M, Toyooka S, Shivapurkar N et al. Aberrant methylation profile of

949 human malignant mesotheliomas and its relationship to SV40 infection. Oncogene.

$950 \quad$ 2005;24(7):1302-1308.

951

46. Paik PK, Krug LM. Histone deacetylase inhibitors in malignant pleural

952

953

954

955

956

957

958

959

960

961

962

963

964

965

966

967

968

969

970

971

mesothelioma: preclinical rationale and clinical trials. J Thorac Oncol. 2010;5(2):275-279.

47. Guled M, Lahti L, Lindholm PM et al. CDKN2A, NF2, and JUN are

dysregulated among other genes by miRNAs in malignant mesothelioma -A miRNA microarray analysis. Genes Chromosomes Cancer. 2009;48(7):615-623.

48. Busacca S, Germano S, De Cecco L et al. MicroRNA signature of malignant mesothelioma with potential diagnostic and prognostic implications. Am J Respir Cell Mol Biol. 2010;42(3):312-319.

49. Gee GV, Koestler DC, Christensen BC et al. Downregulated microRNAs in the differential diagnosis of malignant pleural mesothelioma. Int J Cancer. 2010;127(12):28592869.

50. Ivanov SV, Goparaju CM, Lopez P et al. Pro-tumorigenic effects of miR-31 loss in mesothelioma. J Biol Chem. 2010;285(30):22809-22817.

51. Pass HI, Goparaju C, Ivanov S et al. hsa-miR-29c* is linked to the prognosis of malignant pleural mesothelioma. Cancer Res. 2010;70(5):1916-1924.

52. Benjamin H, Lebanony D, Rosenwald S et al. A diagnostic assay based on microRNA expression accurately identifies malignant pleural mesothelioma. J Mol Diagn. 2010;12(6):771-779.

53. Zekri AR, Bahnassy AA, Mohamed WS et al. Evaluation of simian virus-40 as a biological prognostic factor in Egyptian patients with malignant pleural mesothelioma. Pathol Int. 2007;57(8):493-501. 
972

973

974

975

976

977

978

979

980

981

982

983

984

985

986

987

988

989

990

991

992

993

994

995

54. Jaurand MC, Fleury-Feith J. Pathogenesis of malignant pleural mesothelioma. Respirology. 2005;10(1):2-8.

55. Gee GV, Stanifer ML, Christensen BC et al. SV40 associated miRNAs are not detectable in mesotheliomas. Br J Cancer. 2010;103(6):885-888.

56. Bianchi AB, Mitsunaga S, Cheng J et al. High frequency of inactivating mutations in the neurofibromatosis type 2 gene (NF2) in primary malignant mesothelioma. Proc Natl Acad Sci, USA. 1995;92(24):10854-10858.

57. Sekido Y, Pass HI, Bader S, Mew DJ, Christmas MF, Gazdar AF. Neurofibromatosis type 2 (NF2) gene is somatically mutated in mesothelioma but not in lung cancer. Cancer Res. 1995;55(6):1227-1231.

58. Tiainen M, Tammilehto L, Mattson K, Knuutila S. Nonrandom chromosomal abnormalities in malignant pleural mesothelioma. Cancer Genet Cytogenet. 1988;33(2):251274.

59. Flejter WL, Li FP, Antman KH, Testa JR. Recurring loss involving chromosomes 1,3, and 22 in malignant mesothelioma: possibles sites of tumor suppressor genes. Genes, chromosomes and cancer. 1989;1(2):148-154.

60. Lecomte C, Andujar P, Renier A et al. Similar tumor suppressor gene alteration profiles in asbestos-induced murine and human mesothelioma. Cell Cycle. 2005;4(12):18621869.

61. Andujar P, Wang J, Descatha A et al. p16 ${ }^{\mathrm{INK} 4 \mathrm{~A}}$ inactivation mechanisms in non small-cell lung cancer patients occupationally exposed to asbestos. Lung Cancer. 2010;67(1):23-30.

62. Xiao S, Li DZ, Vijg J, Sugarbaker DJ, Corson JM, Fletcher JA. Codeletion of p15 and p16 in primary malignant mesothelioma. Oncogene. 1995;11(3):511-515. 
63. Takeda M, Kasai T, Enomoto Y et al. 9p21 deletion in the diagnosis of

997 malignant mesothelioma, using fluorescence in situ hybridization analysis. Pathol Int. 998 2010;60(5):395-399.

999 64. Cheng JQ, Jhanwar SC, Klein WM et al. p16 alterations and deletion mapping 1000 of 9p21-p22 in malignant mesothelioma. Cancer Res. 1994;54(21):5547-5551.

1001 65. Kratzke RA, Otterson G, Lincoln CE et al. Immunohistochemical analysis of 1002 the p16INK4 cyclin-dependent kinase inhibitor in malignant mesothelioma. J Natl Cancer 1003 Inst. 1995;87(24):1870-1875.

1004 66. Ladanyi M. Implications of P16/CDKN2A deletion in pleural mesotheliomas. 1005 Lung Cancer. 2005;49 Suppl 1:S95-98.

1006

67. Dacic S, Kothmaier H, Land S et al. Prognostic significance of p16/cdkn2a loss in pleural malignant mesotheliomas. Virchows Arch. 2008;453(6):627-635.

1008 68. Shigemitsu K, Sekido Y, Usami N et al. Genetic alteration of the beta-catenin 1009 gene (CTNNB1) in human lung cancer and malignant mesothelioma and identification of a new 3p21.3 homozygous deletion. Oncogene. 2001;20(31):4249-4257.

1011

69. Uematsu K, Kanazawa S, You L et al. Wnt pathway activation in

1012 mesothelioma: evidence of Dishevelled overexpression and transcriptional activity of beta1013 catenin. Cancer Res. 2003;63(15):4547-4551.

1014 70. Gray SG, Fennell DA, Mutti L, O'Byrne KJ. In arrayed ranks: array technology 1015 in the study of mesothelioma. $J$ Thorac Oncol. 2009;4(3):411-425.

1016 71. Kettunen E, Nissen AM, Ollikainen T et al. Gene expression profiling of 1017 malignant mesothelioma cell lines : cDNA array study. Int J Cancer. 2001;91(4):492-496.

1018 72. Mohr S, Keith G, Galateau-Salle F, Icard P, Rihn BH. Cell protection, 1019 resistance and invasiveness of two malignant mesotheliomas as assessed by 10K-microarray. 1020 Biochim Biophys Acta. 2004;1688(1):43-60. 
1021

1022

1023

1024

1025

1026

1027

1028

1029

1030

1031

1032

1033

1034

1035

1036

1037

1038

1039

1040

1041

1042

1043

1044

73. Mohr S, Bottin MC, Lannes B et al. Microdissection, mRNA amplification and microarray: a study of pleural mesothelial and malignant mesothelioma cells. Biochimie. 2004;86(1):13-19.

74. Kettunen E, Nicholson AG, Nagy B et al. L1CAM, INP10, P-cadherin, tPA and ITGB4 over-expression in malignant pleural mesotheliomas revealed by combined use of cDNA and tissue microarray. Carcinogenesis. 2005;26(1):17-25.

75. Gordon GJ, Rockwell GN, Jensen RV et al. Identification of novel candidate oncogenes and tumor suppressors in malignant pleural mesothelioma using large-scale transcriptional profiling. Am J Pathol. 2005;166(6):1827-1840.

76. Singhal S, Wiewrodt R, Malden LD et al. Gene expression profiling of malignant mesothelioma. Clin Cancer Res. 2003;9(8):3080-3097.

77. Crispi S, Calogero RA, Santini M et al. Global gene expression profiling of human pleural mesotheliomas: identification of matrix metalloproteinase 14 (MMP-14) as potential tumour target. PLoS One. 2009;4(9):e7016.

78. Romagnoli S, Fasoli E, Vaira V et al. Identification of potential therapeutic targets in malignant mesothelioma using cell-cycle gene expression analysis. Am J Pathol. 2009;174(3):762-770.

79. Ivanova AV, Ivanov SV, Prudkin L et al. Mechanisms of FUS1/TUSC2 deficiency in mesothelioma and its tumorigenic transcriptional effects. Mol Cancer. 2009;8:91.

80. Hoang CD, D'Cunha J, Kratzke MG et al. Gene expression profiling identifies matriptase overexpression in malignant mesothelioma. Chest. 2004;125(5):1843-1852.

81. Gordon GJ, Jensen RV, Hsiao LL et al. Using gene expression ratios to predict outcome among patients with mesothelioma. J Natl Cancer Inst. 2003;95(8):598-605. 
82. Gordon GJ, Rockwell GN, Godfrey PA et al. Validation of genomics-based

1046 prognostic tests in malignant pleural mesothelioma. Clin Cancer Res. 2005;11(12):4406-

10474414.

1048 83. Gordon GJ, Dong L, Yeap BY et al. Four-gene expression ratio test for

1049 survival in patients undergoing surgery for mesothelioma. J Natl Cancer Inst.

1050 2009;101(9):678-686.

1051 84. Glinsky GV, Berezovska O, Glinskii AB. Microarray analysis identifies a

1052 death-from-cancer signature predicting therapy failure in patients with multiple types of

1053 cancer. J Clin Invest. 2005;115(6):1503-1521.

1054 85. Crispi S, Fagliarone C, Biroccio A et al. Antiproliferative effect of Aurora

1055 kinase targeting in mesothelioma. Lung Cancer. 2010;70(3):271-279.

1056 86. Ivanova AV, Goparaju CM, Ivanov SV et al. Protumorigenic role of HAPLN1

1057 and its IgV domain in malignant pleural mesothelioma. Clin Cancer Res. 2009;15(8):2602-

10582611.

1059 87. Yang X, Sun X. Meta-analysis of several gene lists for distinct types of cancer:

1060 A simple way to reveal common prognostic markers. BMC Bioinformatics. 2007;8(1):118.

1061 88. Roe OD, Anderssen E, Sandeck H, Christensen T, Larsson E, Lundgren S.

1062 Malignant pleural mesothelioma: genome-wide expression patterns reflecting general

1063 resistance mechanisms and a proposal of novel targets. Lung Cancer. 2010;67(1):57-68.

1064 89. Lemmon MA, Schlessinger J. Cell signaling by receptor tyrosine kinases. Cell. 1065 2010;141(7):1117-1134.

1066 90. Edwards JG, Swinson DE, Jones JL, Waller DA, O'Byrne KJ. EGFR 1067 expression: associations with outcome and clinicopathological variables in malignant pleural 1068 mesothelioma. Lung Cancer. 2006;54(3):399-407. 
1069

1070

1071

1072

1073

1074

1075

1076

1077

1078

1079

1080

1081

1082

1083

1084

1085

1086

1087

1088

1089

1090

1091

1092

91. Kothmaier H, Quehenberger F, Halbwedl I et al. EGFR and PDGFR

differentially promote growth in malignant epithelioid mesothelioma of short and long term survivors. Thorax. 2008;63(4):345-351.

92. Destro A, Ceresoli GL, Falleni M et al. EGFR overexpression in malignant pleural mesothelioma. An immunohistochemical and molecular study with clinicopathological correlations. Lung Cancer. 2006;51(2):207-215.

93. Agarwal V, Lind MJ, Cawkwell L. Targeted epidermal growth factor receptor therapy in malignant pleural mesothelioma: Where do we stand? Cancer Treat Rev. 2010.

94. Govindan R, Kratzke RA, Herndon JE, 2nd et al. Gefitinib in patients with malignant mesothelioma: a phase II study by the Cancer and Leukemia Group B. Clin Cancer Res. 2005;11(6):2300-2304.

95. Jackman DM, Kindler HL, Yeap BY et al. Erlotinib plus bevacizumab in previously treated patients with malignant pleural mesothelioma. Cancer. 2008;113(4):808814.

96. Garland LL, Rankin C, Gandara DR et al. Phase II study of erlotinib in patients with malignant pleural mesothelioma: a Southwest Oncology Group Study. J Clin Oncol. 2007;25(17):2406-2413.

97. Butnor KJ, Burchette JL, Sporn TA, Hammar SP, Roggli VL. The spectrum of Kit (CD117) immunoreactivity in lung and pleural tumors: a study of 96 cases using a singlesource antibody with a review of the literature. Arch Pathol Lab Med. 2004;128(5):538-543.

98. Horvai AE, Li L, Xu Z, Kramer MJ, Jablons DM, Treseler PA. c-Kit is not expressed in malignant mesothelioma. Mod Pathol. 2003;16(8):818-822.

99. Lee AY, Raz DJ, He B, Jablons DM. Update on the molecular biology of malignant mesothelioma. Cancer. 2007;109(8):1454-1461. 
1093

1094

1095

1096

1097

1098

1099

1100

1101

1102

1103

1104

1105

1106

1107

1108

1109

1110

1111

1112

1113

1114

1115

1116

1117

100. Kumar-Singh S, Weyler J, Martin MJ, Vermeulen PB, Van Marck E.

Angiogenic cytokines in mesothelioma: a study of VEGF, FGF-1 and -2, and TGF beta expression. J Pathol. 1999;189(1):72-78.

101. Aoe K, Hiraki A, Tanaka T et al. Expression of vascular endothelial growth factor in malignant mesothelioma. Anticancer Res. 2006;26(6C):4833-4836.

102. Demirag F, Unsal E, Yilmaz A, Caglar A. Prognostic significance of vascular endothelial growth factor, tumor necrosis, and mitotic activity index in malignant pleural mesothelioma. Chest. 2005;128(5):3382-3387.

103. Ohta Y, Shridhar V, Bright RK et al. VEGF and VEGF type C play an important role in angiogenesis and lymphangiogenesis in human malignant mesothelioma tumours. Br J Cancer. 1999;81(1):54-61.

104. Konig J, Tolnay E, Wiethege T, Muller K. Co-expression of vascular endothelial growth factor and its receptor flt-1 in malignant pleural mesothelioma. Respiration. 2000;67(1):36-40.

105. Strizzi L, Catalano A, Vianale G et al. Vascular endothelial growth factor is an autocrine growth factor in human malignant mesothelioma. J Pathol. 2001;193(4):468-475.

106. Filho AL, Baltazar F, Bedrossian C, Michael C, Schmitt FC.

Immunohistochemical expression and distribution of VEGFR-3 in malignant mesothelioma. Diagn Cytopathol. 2007;35(12):786-791.

107. Masood R, Kundra A, Zhu S et al. Malignant mesothelioma growth inhibition by agents that target the VEGF and VEGF-C autocrine loops. Int J Cancer. 2003;104(5):603610.

108. Romano M, Catalano A, Nutini M et al. 5-lipoxygenase regulates malignant mesothelial cell survival: involvement of vascular endothelial growth factor. FASEB J. 2001;15(13):2326-2336. 
109. Pasello G, Favaretto A. Molecular targets in malignant pleural mesothelioma

1119

1120

1121

1122

1123

1124

1125

1126

1127

1128

1129

1130

1131

1132

1133

1134

1135

1136

1137

1138

1139

1140

1141

treatment. Curr Drug Targets. 2009;10(12):1235-1244.

110. Gerwin BI, Lechner JF, Reddel RR et al. Comparison of production of transforming growth factor-beta and platelet-derived growth factor by normal human mesothelial cells and mesothelioma cell lines. Cancer Res. 1987;47(23):6180-6184.

111. Versnel MA, Claesson-Welsh L, Hammacher A et al. Human malignant

mesothelioma cell lines express PDGF beta-receptors whereas cultured normal mesothelial cells express predominantly PDGF alpha-receptors. Oncogene. 1991;6(11):2005-2011.

112. Ramael M, Buysse C, van den Bossche J, Segers K, van Marck E. Immunoreactivity for the beta chain of the platelet-derived growth factor receptor in malignant mesothelioma and non-neoplastic mesothelium. J Pathol. 1992;167(1):1-4. 113. Zhong J, Gencay MM, Bubendorf L et al. ERK1/2 and p38 MAP kinase control MMP-2, MT1-MMP, and TIMP action and affect cell migration: a comparison between mesothelioma and mesothelial cells. J Cell Physiol. 2006;207(2):540-552.

114. Fredriksson L, Li H, Eriksson U. The PDGF family: four gene products form five dimeric isoforms. Cytokine Growth Factor Rev. 2004;15(4):197-204.

115. Heldin P, Asplund T, Ytterberg D, Thelin S, Laurent TC. Characterization of the molecular mechanism involved in the activation of hyaluronan synthetase by plateletderived growth factor in human mesothelial cells. Biochem J. 1992;283 ( Pt 1):165-170.

116. Jacobson A, Brinck J, Briskin MJ, Spicer AP, Heldin P. Expression of human hyaluronan synthases in response to external stimuli. Biochem J. 2000;348 (Pt 1):29-35. 117. Van der Meeren A, Seddon MB, Betsholtz CA, Lechner JF, Gerwin BI. Tumorigenic conversion of human mesothelial cells as a consequence of platelet-derived growth factor-A chain overexpression. Am J Respir Cell Mol Biol. 1993;8(2):214-221. 
118. Metheny-Barlow LJ, Flynn B, van Gijssel HE, Marrogi A, Gerwin BI.

1143 Paradoxical effects of platelet-derived growth factor-A overexpression in malignant

1144 mesothelioma. Antiproliferative effects in vitro and tumorigenic stimulation in vivo. Am J

1145 Respir Cell Mol Biol. 2001;24(6):694-702.

1146 119. Mathy A, Baas P, Dalesio O, van Zandwijk N. Limited efficacy of imatinib

1147 mesylate in malignant mesothelioma: a phase II trial. Lung Cancer. 2005;50(1):83-86.

1148 120. Porta C, Mutti L, Tassi G. Negative results of an Italian Group for

1149 Mesothelioma (G.I.Me.) pilot study of single-agent imatinib mesylate in malignant pleural

1150 mesothelioma. Cancer Chemother Pharmacol. 2007;59(1):149-150.

1151 121. Whitson BA, Kratzke RA. Molecular pathways in malignant pleural

1152 mesothelioma. Cancer Lett. 2006;239(2):183-189.

1153 122. Jaurand MC, Fleury-Feith J. Mesothelial cells. In: Light RW, Lee YCG, eds.

1154 Textbook of pleural diseases. Second edition. London: Hodder Arnold; 2008:27-37.

1155 123. Hoang CD, Zhang X, Scott PD et al. Selective activation of insulin receptor

1156 substrate-1 and -2 in pleural mesothelioma cells: association with distinct malignant

1157 phenotypes. Cancer Res. 2004;64(20):7479-7485.

1158 124. Lee TC, Zhang Y, Aston C et al. Normal human mesothelial cells and

1159 mesothelioma cell lines express insulin-like growth factor I and associated molecules. Cancer

1160 Res. 1993;53(12):2858-2864.

1161 125. Liu Z, Klominek J. Regulation of matrix metalloprotease activity in malignant

1162 mesothelioma cell lines by growth factors. Thorax. 2003;58(3):198-203.

1163 126. Kawaguchi K, Murakami H, Taniguchi T et al. Combined inhibition of MET

1164 and EGFR suppresses proliferation of malignant mesothelioma cells. Carcinogenesis.

1165 2009;30(7):1097-1105. 
127. Jagadeeswaran R, Ma PC, Seiwert TY et al. Functional analysis of c-

1167

1168

1169

1170

1171

1172

1173

1174

1175

1176

1177

1178

1179

1180

1181

1182

1183

1184

1185

1186

1187

1188

1189

1190

Met/hepatocyte growth factor pathway in malignant pleural mesothelioma. Cancer Res. 2006;66(1):352-361.

128. Tolnay E, Kuhnen C, Wiethege T, Konig JE, Voss B, Muller KM. Hepatocyte growth factor/scatter factor and its receptor c-Met are overexpressed and associated with an increased microvessel density in malignant pleural mesothelioma. J Cancer Res Clin Oncol. 1998;124(6):291-296.

129. Thirkettle I, Harvey P, Hasleton PS, Ball RY, Warn RM. Immunoreactivity for cadherins, HGF/SF, met, and erbB-2 in pleural malignant mesotheliomas. Histopathology. 2000;36(6):522-528.

130. Harvey P, Warn A, Dobbin S et al. Expression of HGF/SF in mesothelioma cell lines and its effects on cell motility, proliferation and morphology. Br J Cancer. 1998;77(7):1052-1059.

131. Mukohara T, Civiello G, Davis IJ et al. Inhibition of the met receptor in mesothelioma. Clin Cancer Res. 2005;11(22):8122-8130.

132. de Melo M, Gerbase MW, Curran J, Pache JC. Phosphorylated extracellular signal-regulated kinases are significantly increased in malignant mesothelioma. $J$ Histochem Cytochem. 2006;54(8):855-861.

133. Vintman L, Nielsen S, Berner A, Reich R, Davidson B. Mitogen-activated protein kinase expression and activation does not differentiate benign from malignant mesothelial cells. Cancer. 2005;103(11):2427-2433.

134. Eguchi R, Fujimori Y, Takeda $\mathrm{H}$ et al. Arsenic trioxide induces apoptosis through JNK and ERK in human mesothelioma cells. J Cell Physiol. 2011;226(3):762-768. 135. Ou WB, Hubert C, Corson JM et al. Targeted inhibition of multiple receptor tyrosine kinases in mesothelioma. Neoplasia. 2011;13(1):12-22. 
136. Roth M, Zhong J, Tamm M, Szilard J. Mesothelioma cells escape heat stress

1192 by upregulating Hsp40/Hsp70 expression via mitogen-activated protein kinases. J Biomed

1193 Biotechnol. 2009;2009:451084.

1194 137. Besson A, Robbins SM, Yong VW. PTEN/MMAC1/TEP1 in signal

1195 transduction and tumorigenesis. Eur J Biochem. 1999;263(3):605-611.

1196 138. Daubriac J, Fleury-Feith J, Kheuang L et al. Malignant pleural mesothelioma

1197 cells resist anoikis as quiescent pluricellular aggregates. Cell Death and Differentiation.

1198 2009;16 (8):1146-1155.

1199 139. Altomare DA, You H, Xiao GH et al. Human and mouse mesotheliomas 1200 exhibit elevated AKT/PKB activity, which can be targeted pharmacologically to inhibit tumor 1201 cell growth. Oncogene. 2005;24(40):6080-6089.

1202 140. Suzuki Y, Murakami H, Kawaguchi K et al. Activation of the PI3K-AKT 1203 pathway in human malignant mesothelioma cells. Molecular Medicine Reports.

1204 2009;2(2):181-188.

1205 141. Opitz I, Soltermann A, Abaecherli M et al. PTEN expression is a strong 1206 predictor of survival in mesothelioma patients. Eur J Cardiothorac Surg. 2008;33(3):502-506.

1207 142. Clevers H. Wnt/beta-catenin signaling in development and disease. Cell. 1208 2006;127(3):469-480.

1209 143. Lee AY, He B, You L et al. Dickkopf-1 antagonizes Wnt signaling 1210 independent of beta-catenin in human mesothelioma. Biochem Biophys Res Commun. $12112004 ; 323(4): 1246-1250$.

1212 144. Mazieres J, You L, He B et al. Wnt2 as a new therapeutic target in malignant 1213 pleural mesothelioma. Int J Cancer. 2005;117(2):326-332. 
145. Kashiwakura Y, Ochiai K, Watanabe M et al. Down-regulation of inhibition of

1215 differentiation-1 via activation of activating transcription factor 3 and Smad regulates

1216 REIC/Dickkopf-3-induced apoptosis. Cancer Res. 2008;68(20):8333-8341.

1217 146. Yokoyama T, Osada H, Murakami H et al. YAP1 is involved in mesothelioma

1218 development and negatively regulated by Merlin through phosphorylation. Carcinogenesis.

1219 2008;29(11):2139-2146.

1220 147. Murakami H, Mizuno T, Taniguchi T et al. LATS2 Is a Tumor Suppressor

1221 Gene of Malignant Mesothelioma. Cancer Res. 2011;71(3):873-883.

1222 148. Thurneysen C, Opitz I, Kurtz S, Weder W, Stahel RA, Felley-Bosco E.

1223 Functional inactivation of NF2/merlin in human mesothelioma. Lung Cancer.

1224 2009;64(2):140-147.

1225 149. Xiao GH, Gallagher R, Shetler J et al. The NF2 tumor suppressor gene product,

1226 merlin, inhibits cell proliferation and cell cycle progression by repressing cyclin D1

1227 expression. Mol Cell Biol. 2005;25(6):2384-2394.

1228 150. Poulikakos PI, Xiao GH, Gallagher R, Jablonski S, Jhanwar SC, Testa JR. Re-

1229 expression of the tumor suppressor NF2/merlin inhibits invasiveness in mesothelioma cells

1230 and negatively regulates FAK. Oncogene. 2006;25(44):5960-5968.

1231 151. Lopez-Lago MA, Okada T, Murillo MM, Socci N, Giancotti FG. Loss of the

1232 tumor suppressor gene NF2, encoding merlin, constitutively activates integrin-dependent

1233 mTORC1 signaling. Mol Cell Biol. 2009;29(15):4235-4249.

1234 152. Song EJ, Yim SH, Kim E, Kim NS, Lee KJ. Human Fas-associated factor 1, 1235 interacting with ubiquitinated proteins and valosin-containing protein, is involved in the 1236 ubiquitin-proteasome pathway. Mol Cell Biol. 2005;25(6):2511-2524. 
153. Altomare DA, Menges CW, Pei J et al. Activated TNF-alpha/NF-kappaB

1238

1239

1240

1241

1242

1243

1244

1245

1246

1247

1248

1249

1250

1251

1252

1253

1254

1255

1256

1257

1258

1259 signaling via down-regulation of Fas-associated factor 1 in asbestos-induced mesotheliomas from Arf knockout mice. Proc Natl Acad Sci U S A. 2009;106(9):3420-3425.

154. Borczuk AC, Cappellini GC, Kim HK, Hesdorffer M, Taub RN, Powell CA.

Molecular profiling of malignant peritoneal mesothelioma identifies the ubiquitin-proteasome pathway as a therapeutic target in poor prognosis tumors. Oncogene. 2007;26(4):610-617.

155. Sun X, Wei L, Liden J et al. Molecular characterization of tumour

heterogeneity and malignant mesothelioma cell differentiation by gene profiling. $J$ Pathol. 2005;207(1):91-101.

156. Sartore-Bianchi A, Gasparri F, Galvani A et al. Bortezomib inhibits nuclear factor-kappaB dependent survival and has potent in vivo activity in mesothelioma. Clin Cancer Res. 2007;13(19):5942-5951.

157. Sun X, Gulyas M, Hjerpe A, Dobra K. Proteasome inhibitor PSI induces apoptosis in human mesothelioma cells. Cancer Lett. 2006;232(2):161-169.

158. Yuan BZ, Chapman JA, Reynolds SH. Proteasome Inhibitor MG132 Induces Apoptosis and Inhibits Invasion of Human Malignant Pleural Mesothelioma Cells. Transl Oncol. 2008;1(3):129-140.

159. Gordon GJ, Mani M, Maulik G et al. Preclinical studies of the proteasome inhibitor bortezomib in malignant pleural mesothelioma. Cancer Chemother Pharmacol. 2008;61(4):549-558.

160. Barbone D, Yang TM, Morgan JR, Gaudino G, Broaddus C. Mammalian target of rapamycin contributes to the acquired apoptotic resistance of human mesothelioma multicellular spheroids. J Biol Chem. 2008;283(19):13021-11330. 
161. Frizelle SP, Grim J, Zhou J et al. Re-expression of p16INK4a in mesothelioma

1261 cells results in cell cycle arrest, cell death, tumor suppression and tumor regression.

1262 Oncogene. 1998;16(24):3087-3095.

1263 162. Yang CT, You L, Yeh CC et al. Adenovirus-mediated p14ARF gene transfer in 1264 human mesothelioma cells. J Natl Cancer Inst. 2000;92(8):636-641.

1265 163. Yang CT, You L, Uematsu K, Yeh CC, Mc Cormick F, Jablons DM. p14ARF

1266 modulates the cytolytic effect of ONYX-015 in mesothelioma cells with wild-type p53.

1267 Cancer Res. 2001;61(16):5959-5963.

1268 164. Kim KW, Mutter RW, Willey CD et al. Inhibition of survivin and aurora B 1269 kinase sensitizes mesothelioma cells by enhancing mitotic arrests. Int J Radiat Oncol Biol 1270 Phys. 2007;67(5):1519-1525.

1271 165. Kim JY, Harvard C, You L et al. Stathmin is overexpressed in malignant 1272 mesothelioma. Anticancer Res. 2007;27(1A):39-44.

1273 166. Wu YJ, Parker LM, Binder NE et al. The mesothelial keratins: a new family of 1274 cytoskeletal proteins identified in cultured mesothelial cells and nonkeratinizing epithelia. 1275 Cell. 1982;31(3 Pt 2):693-703.

1276 167. Vivo C, Lecomte C, Levy F et al. Cell cycle checkpoint status in human 1277 malignant mesothelioma cell lines: response to gamma radiation. Br J Cancer. $1278 \quad$ 2003;88(3):388-395.

1279 168. Bunderson-Schelvan M, Erbe AK, Schwanke C, Pershouse MA. Suppression 1280 of the mouse double minute 4 gene causes changes in cell cycle control in a human 1281 mesothelial cell line responsive to ultraviolet radiation exposure. Environ Mol Mutagen. $1282 \quad$ 2009;50(9):753-759.

1283 169. Robinson BW, Musk AW, Lake RA. Malignant mesothelioma. Lancet. $1284 \quad$ 2005;366(9483):397-408. 
170. Jin L, Amatya VJ, Takeshima Y, Shrestha L, Kushitani K, Inai K. Evaluation

1286

1287

1288

1289

1290

1291

1292

1293

1294

1295

1296

1297

1298

1299

1300

1301

1302

1303

1304

1305

1306

1307

1308 of apoptosis and immunohistochemical expression of the apoptosis-related proteins in mesothelioma. Hiroshima J Med Sci. 2010;59(2):27-33.

171. Lu Q, Harrington EO, Rounds S. Apoptosis and lung injury. Keio J Med. 2005;54(4):184-189.

172. Liu W, Bodle E, Chen JY, Gao M, Rosen GD, Broaddus VC. Tumor necrosis factor-related apoptosis-inducing ligand and chemotherapy cooperate to induce apoptosis in mesothelioma cell lines. Am J Respir Cell Mol Biol. 2001;25(1):111-118.

173. Rippo MR, Moretti S, Vescovi S et al. FLIP overexpression inhibits death receptor-induced apoptosis in malignant mesothelial cells. Oncogene. 2004;23(47):77537760.

174. Tomasetti M, Rippo MR, Alleva R et al. Alpha-tocopheryl succinate and TRAIL selectively synergise in induction of apoptosis in human malignant mesothelioma cells. Br J Cancer. 2004;90(8):1644-1653.

175. Abayasiriwardana KS, Barbone D, Kim KU et al. Malignant mesothelioma cells are rapidly sensitized to TRAIL-induced apoptosis by low-dose anisomycin via Bim. Mol Cancer Ther. 2007;6(10):2766-2776.

176. Pespeni MH, Hodnett M, Abayasiriwardana KS et al. Sensitization of mesothelioma cells to tumor necrosis factor-related apoptosis-inducing ligand-induced apoptosis by heat stress via the inhibition of the 3-phosphoinositide-dependent kinase 1/Akt pathway. Cancer Res. 2007;67(6):2865-2871.

177. Katz SI, Zhou L, Chao G et al. Sorafenib inhibits ERK1/2 and MCL-1(L) phosphorylation levels resulting in caspase-independent cell death in malignant pleural mesothelioma. Cancer Biol Ther. 2009;8(24):2406-2416. 
178. Wilson SM, Barbone D, Yang TM et al. mTOR mediates survival signals in malignant mesothelioma grown as tumor fragment spheroids. Am J Respir Cell Mol Biol. 2008;39(5):576-583.

1313 Apoptosis and expression of apoptosis regulating proteins bcl-2, mcl-1, bcl-X, and bax in 1314 malignant mesothelioma. Clin Cancer Res. 1999;5(11):3508-3515.

1315 180. Smythe WR, Mohuiddin I, Ozveran M, Cao XX. Antisense therapy for 1316 malignant mesothelioma with oligonucleotides targeting the bcl-xl gene product. $J$ Thorac 1317 Cardiovasc Surg. 2002;123(6):1191-1198.

1318 181. Cao X, Rodarte C, Zhang L, Morgan CD, Littlejohn J, Smythe WR. Bcl2/bcl1319 xL inhibitor engenders apoptosis and increases chemosensitivity in mesothelioma. Cancer 1320 Biol Ther. 2007;6(2):246-252.

1321 182. Littlejohn JE, Cao X, Miller SD et al. Bcl-xL antisense oligonucleotide and 1322 cisplatin combination therapy extends survival in SCID mice with established mesothelioma 1323 xenografts. Int J Cancer. 2008;123(1):202-208.

1324 183. Varin E, Denoyelle C, Brotin E et al. Downregulation of Bcl-xL and Mcl-1 is 1325 sufficient to induce cell death in mesothelioma cells highly refractory to conventional 1326 chemotherapy. Carcinogenesis. 2010;31(6):984-993.

1327 184. O'Kane SL, Pound RJ, Campbell A, Chaudhuri N, Lind MJ, Cawkwell L. 1328 Expression of bcl-2 family members in malignant pleural mesothelioma. Acta Oncol. 1329 2006;45(4):449-453.

1330 185. Xia C, Xu Z, Yuan X et al. Induction of apoptosis in mesothelioma cells by 1331 antisurvivin oligonucleotides. Mol Cancer Ther. 2002;1(9):687-694. 
186. Zaffaroni N, Costa A, Pennati M et al. Survivin is highly expressed and

1333 promotes cell survival in malignant peritoneal mesothelioma. Cell Oncol. 2007;29(6):453-

1334

1335

1336

1337

1338

1339

1340

1341

1342

1343

1344

1345

1346

1347

1348

1349

1350

1351

1352 466.

187. Kleinberg L, Lie AK, Florenes VA, Nesland JM, Davidson B. Expression of inhibitor-of-apoptosis protein family members in malignant mesothelioma. Hum Pathol. 2007;38(7):986-994.

188. Symanowski J, Vogelzang N, Zawel L, Atadja P, Pass H, Sharma S. A histone deacetylase inhibitor LBH589 downregulates XIAP in mesothelioma cell lines which is likely responsible for increased apoptosis with TRAIL. J Thorac Oncol. 2009;4(2):149-160.

189. Dhaene K, Hübner R, Kumar-Singh S, Weyn B, Van Marck E. Telomerase activity in human pleural mesothelioma. Thorax. 1998;53(11):915-918.

190. Villa R, Daidone MG, Motta R et al. Multiple mechanisms of telomere maintenance exist and differentially affect clinical outcome in diffuse malignant peritoneal mesothelioma. Clin Cancer Res. 2008;14(13):4134-4140.

191. Catalano A, Romano M, Robuffo I, Strizzi L, Procopio A. Methionine aminopeptidase-2 regulates human mesothelioma cell survival. Role of Bcl-2 expression and telomerase activity. Am J Pathol. 2001;159(2):721-731.

192. Amin W, Parwani AV, Schmandt L et al. National Mesothelioma Virtual Bank: a standard based biospecimen and clinical data resource to enhance translational research. BMC Cancer. 2008;8:236. 